Article

\title{
Low Temperature District Heating: An Expert Opinion Survey
}

\author{
Alessandro Guzzini, Marco Pellegrini * (D), Edoardo Pelliconi and Cesare Saccani \\ Department of Industrial Engineering (DIN), University of Bologna, 40136 Bologna, Italy; \\ alessandro.guzzini2@unibo.it (A.G.); edoardo.pelliconi2@unibo.it (E.P.); cesare.saccani@unibo.it (C.S.) \\ * Correspondence: marco.pellegrini3@unibo.it
}

Received: 16 January 2020; Accepted: 8 February 2020; Published: 13 February 2020

\begin{abstract}
Among the available solutions for building heating and cooling, district heating (DH) and district cooling (DC) systems are considered some of the best options since they can ensure a better control of pollutant emissions and greater efficiency than individual systems. Nevertheless, improvements are needed to increase their sustainability and reliability. The so-called "low temperature district heating" (LTDH) concept has been introduced in recent years in an attempt (i) to reduce the distribution heat losses through a temperature decrease in the DH network, (ii) to favor the integration with renewable energy sources, and (iii) to create the conditions required for the development of future smart energy systems. However, many concerns have been raised about its implementation in both existing and new systems. For this reason, this paper aims to identify the stakeholders' ranking of the barriers against LTDH system development and implementation over the next few years. Aiming to this, a questionnaire was designed, including an analysis of current gaps and strengths, and then submitted to more than 50 Italian and international experts in the field of DH. An in-depth analysis of the received answers was performed, focusing in particular on the Italian experts' answers. Comments and suggestions on how to promote the transition to the new LTDH approach are reported.
\end{abstract}

Keywords: district heating (DH); district cooling (DC); low temperature district heating (LTDH); expert opinion survey

\section{Introduction}

Energy market decarbonization represents a challenging goal for decision makers who have to evaluate many complex factors that are involved, such as human behaviors, social acceptability, economic costs, available infrastructures, markets, and governance [1]. Therefore, the identification of the best energy strategy results is very difficult. Since space heating and cooling account for almost one-third of the total world energy consumption [2], new energy strategies are needed as soon as possible in the domestic and residential sector. In particular, district heating (DH) is considered one of the most interesting options to achieve Energy Roadmap 2050 targets [3]. Several studies have aimed to demonstrate the higher efficiency and lower environmental impact with respect to traditional decentralized heating systems [4-8]. Furthermore, better safety performances are expected to prevent natural gas distribution in very populated areas [9]. For these reasons, more than $80,000 \mathrm{DH}$ networks, that supplied almost 11,5 EJ of heat to industries and buildings in 2014, are present worldwide [10].

Several solutions have been proposed through the years, aiming to gradually reduce the distribution temperature of $\mathrm{DH}$ systems and thus to improve energy performances. Furthermore, renewable heating sources have been progressively implemented in DH systems, including geothermal heat pumps [11-13], biomass thermal plants [14-16], and solar plants [17]. In addition to energy efficiency improvement, economic considerations move DH stakeholders to reduce distribution 
temperature. In fact, lower thermal losses are suggested to improve the economic competitiveness of DH systems [18-20]. Furthermore, due to the decrease in the mean electricity selling price, in certain working conditions, traditional natural gas boilers are preferred to Combined Heat and Power (CHP) plants by DH companies in order to maximize profit, despite the lower efficiency [21].

To improve both efficiency and economic DH performances, the 4th DH generation, also called "low temperature district heating" (LTDH), was first proposed in 2014 [22]. In particular, four minimum requirements were identified: (i) the ability to supply low-temperature thermal energy to new and existing buildings, (ii) the capacity to reduce thermal losses along the network, (iii) the ability to integrate low enthalpy heat plants maintaining the current supply conditions, and (iv) to become a part of smart energy systems and thus to contribute to the transition towards a $100 \%$ renewable energy supply system between which different energy sectors are integrated. The LTDH definition identifies a wide range of temperatures: for example, a preliminary classification is proposed in [23] where "warm LTDH" and "cold LTDH" systems are introduced based on the need or not to locally boost the temperature to the customer level. In [24], three different LTDH systems are defined on the basis of distributing temperature: "low temperature" systems $\left(55 / 25^{\circ} \mathrm{C}\right)$, "ultra-low temperature with electric boosting" systems $\left(45 / 25^{\circ} \mathrm{C}\right)$, and "ultra-low temperature with heat pump boosting" systems $(35 / 20$ $\left.{ }^{\circ} \mathrm{C}\right)$. Despite the absence of a defined range of temperatures, many positive outcomes can be recognized because of the implementation of the LTDH concept. First of all, a reduction of the capital expenditures (CAPEX) and of the operative expenditures (OPEX) is expected due to the lower temperature and thermal losses $[25,26]$. Secondly, a more favorable utilization of several low enthalpy heat sources is estimated even if different configurations $[27,28]$ have to be evaluated. In particular, many technologies such as photovoltaic (PV) panels [29,30], heat pumps [31], solar thermal collectors [32,33], and hybrid PV panels $[34,35]$ can start to be considered for LTDH applications. Despite the positive outcomes, many barriers hamper LTDH implementation. First of all, a reduction of thermal heat transfer is expected. In fact, even if no standardized definition of LTDH temperature ranges is available in the literature $[13,36,37]$, the ability to ensure the existing supply conditions to customers remains a priority for the success of LTDH. To verify the effects of temperature reduction at the supply side on existing systems, the occurrence of uncomfortable thermal conditions was experimentally assessed, and the results were not relevant or critical for customers [38,39]. Nevertheless, these two results in domestic and residential sectors cannot be considered generally applicable due to the limited numbers of investigated case studies. Nevertheless, the substitution or retrofitting of existing heat exchangers installed in DH substations, or of the household radiators, would represent an important economic barrier for the massive LTDH implementation. Secondly, a new figure, i.e., the prosumer, has appeared in the LTDH market, and requires bi-directional energy metering and new management and control demands $[40,41]$. Furthermore, regulatory changes are needed to help the always increasing integration and interchangeability $[37,42,43]$. Finally, other technical challenges have been recognized in the literature [44,45], such as the occurrence of substation faults [46,47], the flow recirculation in the case of low thermal demand $[27,48]$, and the presence of suitable conditions for legionella proliferation in Domestic Hot Water (DHW) storage tanks (boilers) [49,50].

Therefore, many investigations have been performed through the years, but they principally account for technological issues in the Northern European framework. To overcome this research limit, existing technological and non-technological barriers for LTDH implementation were investigated in an initial paper by our team with a specific focus on the Italian framework, considered representative of Southern European Countries [51]. This paper aims to assess the LTDH barriers ranking through an expert opinion survey. The survey was designed to include an analysis of current DH gaps and strengths, and then submitted to more than 50 Italian and international experts in the field of DH and DC, as described in the second part of the paper regarding methodology. In the third section, via an in-depth analysis of the given answers, criticalities and potentials of the LTDH approach are recognized in order to suggest dedicated technological and non-technological solutions. A comparison between the answers of the Italian experts and the other ones was made to underline if differences and/or similarities 
can be found. Final comments about the existing criticalities of LTDH development were lastly reported in the conclusion for government bodies, policy owners, and all other potential stakeholders.

\section{Materials and Methods}

Several examples of expert opinion surveys can be found in the literature. For example, the authors in [52] analyzed the potential of renewable hydrogen systems in Europe, the authors in [53] assessed the future battery cost for electric and plug-in hybrid vehicles, the authors in [54] investigated photovoltaic and concentrated solar power technologies, and the authors in [55] examined the expected future cost of advanced biofuels. Indeed, as reported in [56], expert opinion surveys are very useful for analyzing concepts that will be, in other cases, very difficult or impossible to measure through other traditional methods. However, several considerations are needed to design an expert opinion survey.

First of all, experts have to be recognized. For this purpose, it was decided to apply the definition in [57], i.e., a person "trained by practice" or "skilled," while the noun "expert" carries the additional meaning of "one whose special knowledge causes him to be an authority" or "a specialist" for the sector. Because different organizations are interested in DH technology, the experts were identified in both private and public companies, universities, private research centers, and $\mathrm{DH}$ sector organizations. A minimum number of experts is needed to ensure statistical confidence in the survey results. A minimum number of 50 participants was considered. For this purpose, the invitation to participate was sent to more than 50 worldwide sector experts with whom we were in contact. For confidentiality reasons, the names of the experts are not reported in this paper. Furthermore, to increase the number of participants, DH international associations (Table 1) were asked to share their survey with their members. In particular, association selection was based on the relevance of DH in the country. The countries that participated in the survey with at least one participant are shown in Figure 1.

Table 1. Invited association to the proposed expert opinion survey.

\begin{tabular}{|c|c|c|}
\hline DH Association Invited to the Survey & Country & $\begin{array}{l}\text { Positively Answered to the } \\
\text { Invitation }\end{array}$ \\
\hline $\begin{array}{l}\text { Associazione Italiana Riscaldamento } \\
\text { Urbano (AIRU) }\end{array}$ & Italy & $x$ \\
\hline $\begin{array}{l}\text { Associazione Svizzera di } \\
\text { Teleriscaldamento (AST) }\end{array}$ & Switzerland & $x$ \\
\hline $\begin{array}{l}\text { Finnish District Heating and Cooling } \\
\text { Association }\end{array}$ & Finland & $x$ \\
\hline AGFW & Germany & $x$ \\
\hline UK District Energy Association & UK & $x$ \\
\hline Polish District Heating & Poland & \\
\hline $\begin{array}{c}\text { Hellenic Association for Cogeneration of } \\
\text { Heat \& Power }\end{array}$ & Greece & \\
\hline Norsk Fjernvarme & Norway & \\
\hline Japan Heat Supply Business Association & Japan & \\
\hline China District Heating Association & China & \\
\hline Center for Energy Efficiency & Russia & \\
\hline Euroheat \& Power & NA $(*)$ & $x$ \\
\hline International District Energy Association & NA $(*)$ & $x$ \\
\hline Asia Pacific Urban Energy Association & NA $(*)$ & \\
\hline
\end{tabular}

$\left({ }^{*}\right)$ Euroheat \& Power and the International District Energy Association, respectively, located in Belgium and in the United States of America, including members from different countries. 


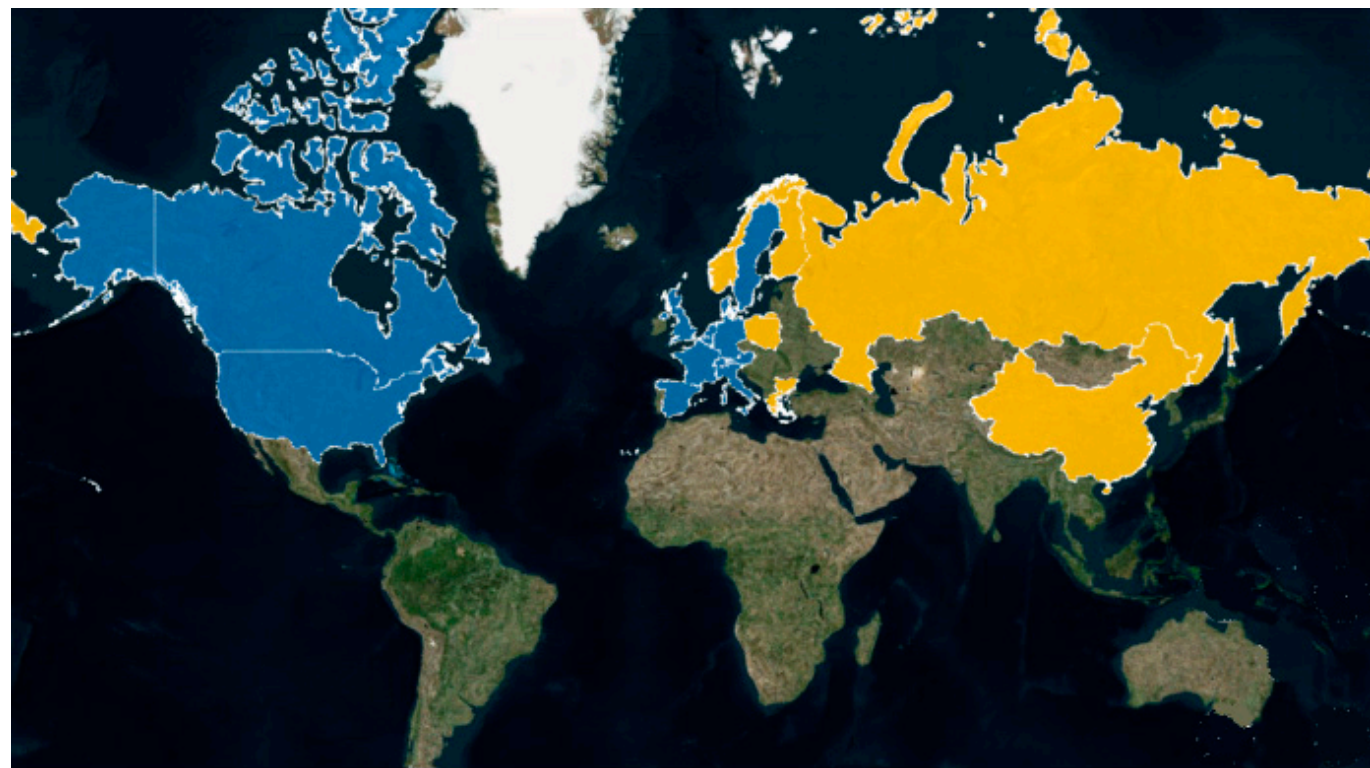

Countries that have at least one participant

Countries that were invited to the survey but did not participate

Figure 1. Countries that have at least one participant and countries that were invited to the survey but did not participate.

Since literature is poor about LTDH applications in Southern European Countries and particularly in Italy, we decided to give more relevance to that area by inviting a greater number of Italian experts. Therefore, in addition to the general data analysis, two separated assessments (answers from Italy and from other countries) were performed.

To design the survey, a clear identification of the questions was needed. In particular, because of the survey's aim, the questions were prepared to identify the advantages and disadvantages of traditional DH and LTDH as well as the main technical and non-technical barriers against LTDH implementation. In particular, all technical, economic, regulatory, and authorization aspects were covered, and experts were asked to rank them. We preferred to not specify LTDH in terms of temperature, i.e., warm and cold LTDH. Therefore, the definition found in [22], where no unambiguous definition of temperature ranges is present, had to be considered for answer analysis. Even if some concerns arise from this decision, it should be noted that no standardized definition of LTDH temperature ranges exists. Therefore, the most generic definition was considered to prevent participants from misunderstanding.

Regarding the survey design, three main sections were considered. The complete list of questions and answers, however, is given in Tables A1 and A2 in the Appendix A. In the first section, five questions were proposed to categorize participants and to be used in the following sections to perform a multi-parametric investigation. A summarized list of main data is proposed:

1. Organization type (Q1.1). Different organization types were considered for the purpose of the analysis: (i) private and (ii) public companies, (iii) universities, (iv) private research centers, (v) authorities, (vi) self-employment operations, and (vii) other.

2. Organization location (Q1.2). This information was considered essential to characterize participants' opinions as a function of country and thus to recognize differences.

3. Expertise area within the organization (Q1.3). Depending on the expertise area within the organization, different opinions were expected. Participants were asked to select one among: (i) energy planning, (ii) R\&D, (iii) technical design, (iv) management, (v) business development, (vi) administrative/legal/authoritative, and (vii) other.

4. Expertise area in district heating (Q1.4). Because differences in expertise area were possible, specifically regarding $\mathrm{DH}$, participants were asked to specify it. 
5. Experience in DH sector (Q1.5). Participants' experience is proportional to the expected knowledge of the DH sector. Four options were proposed: (i) less than 2 years, (ii) between 2 and 5 years, (iii) between 5 and 10 years, and (iv) more than 10 years.

The second section of the survey aimed to identify when and how one first became aware of the LTDH concept. In particular, three questions were asked:

1. Awareness about the LTDH concept (Q2.1). Two possible answers were given. Regarding participants that had never heard about the LTDH concept, the survey was designed to omit their answers about the LTDH concept.

2. First temporal awareness of the LTDH concept (Q2.2). This question was introduced to recognize the temporal evolution of the 4 th generation of the DH sector. For this purpose, four possible answers were suggested: (i) before 2000, (ii) between 2000 and 2010, (iii) between 2010 and 2017, and (iv) this year, i.e., in 2018.

3. First approach communication channels (Q2.3). With the received answers, it was possible to identify the dissemination potential and thus to give suggestions for future improvement. The following options were suggested: (i) sector conference/seminar/workshop, (ii) peer-reviewed papers, (iii) technical magazines/newspapers, (iv) internet sites, (v) plant visits, and (vi) other.

In the third section, questions focusing on more technical aspects of DH and LTDH systems were proposed to recognize participants' opinion:

1. Advantages of the existing DH systems with respect to conventional individual heating systems installed in the buildings (Q3.1). To answer the questions, several possible advantages were identified in accordance with the existing literature [58-64].

2. Disadvantages of the existing DH systems with respect to conventional individual heating systems installed in the buildings (Q3.2). As for advantages, disadvantages were also selected based on those reported in the literature.

3. Advantages of LTDH systems with respect to traditional DH systems (Q3.3). Regarding traditional DH systems, the proposed options were identified based on those reported in literature.

4. Disadvantages of LTDH systems with respect to traditional DH systems (Q3.4).

5. LTDH barriers' ranking (Q3.5). Participants were asked to give a rank between 1 (very low importance) and 5 (very high importance) to several technical, economic, and other barriers that could obstruct LTDH market development.

6. Market development of the LTDH concept (Q3.6). Experts were asked to comment on the diffusion of the LTDH concept over the next 20 years.

Concerning possible answers, we decided to minimize open-form questions as much as possible. In fact, even though open-form questions permit spontaneous responses and avoid the bias derived from the suggestion of answers [65], the possible high number of different responses to the same question would have been critical for data collection and elaboration. Furthermore, a minimum number of open-ended questions was proposed to prevent participants from not finishing the survey [66]. Therefore, we decided to use closed-form and multiple-choice questions. Furthermore, participants could select the option "other." In this case, the answer was carefully analyzed in order to understand if it could be lead back to one of the other suggested answers. Although 77 experts started the questionnaire, only 58 of them answered all the questions, i.e., $75.3 \%$. Therefore, regarding participants that did not complete the survey, only questions that were fully answered were considered. 


\section{Results and Discussion}

\subsection{Identification of Participants' Status}

Participants' status identification was the first step of the survey. Concerning countries in which the participants' organizations operate, Italy was the most represented with 44 participants, followed by Denmark with 12 participants (Figure 2).

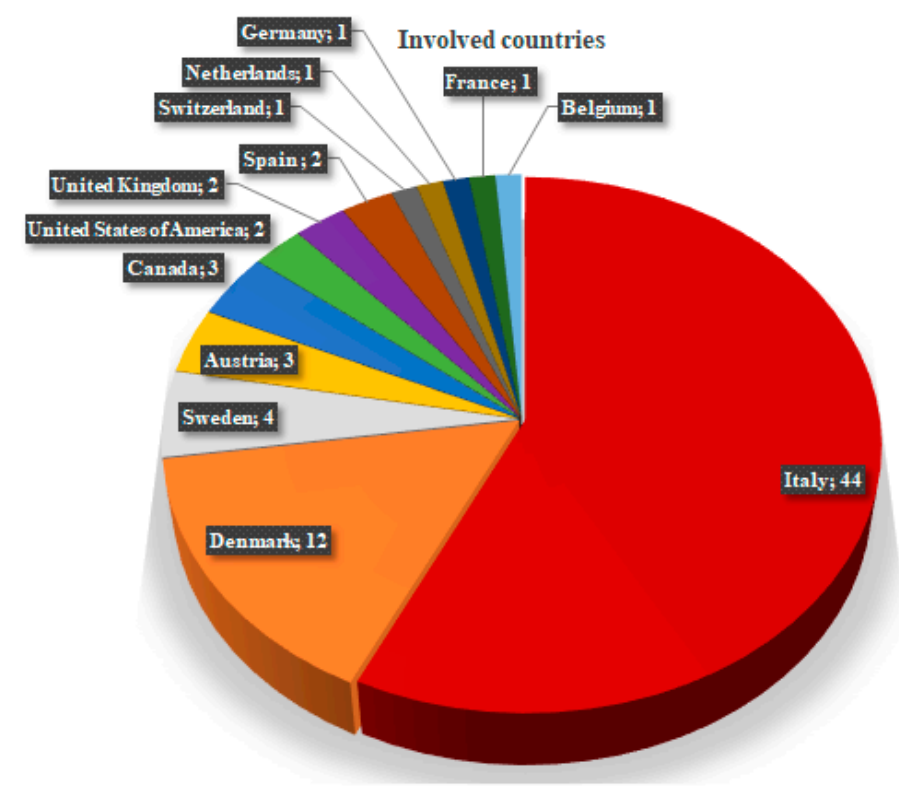

Figure 2. Number of participants from each country.

Regarding the organization type (Figure 3), the greatest percentage of participants works in private companies (33.8\%), followed by universities (24.7\%), public companies $(18.2 \%)$, public authorities $(6.5 \%)$, private research centers $(5.2 \%)$, self-employment operations, $(3.9 \%)$ and other types $(7.8 \%)$. In particular, it is clear that Italian participants mainly come from private companies, while universities are the primary type of organization from which participants from other countries come.

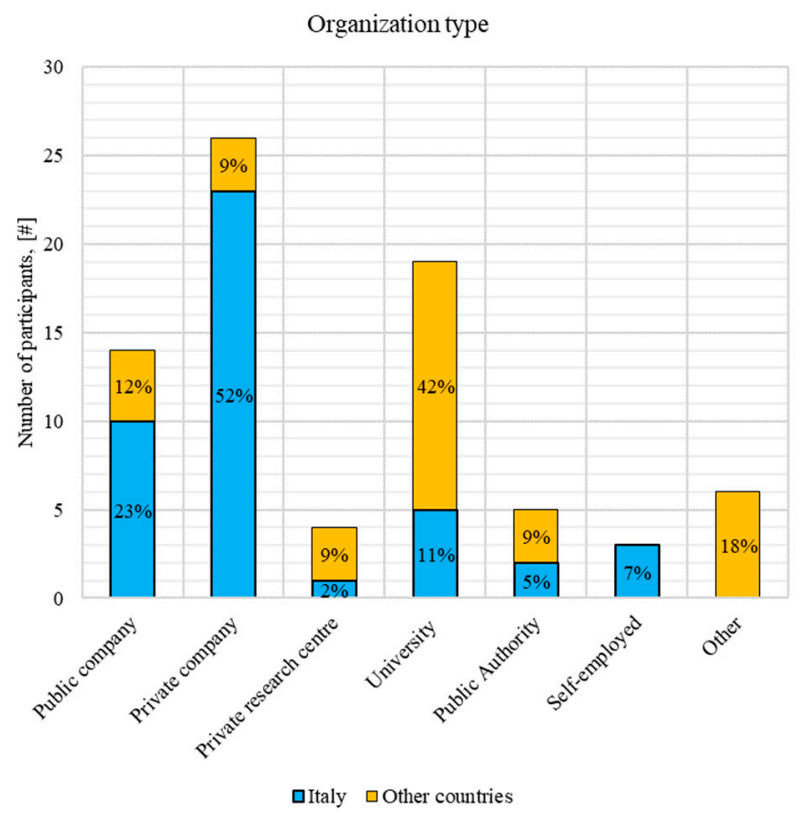

Figure 3. Number of survey participants as a function of the organization type. 
With attention to participants' role within the organization (Figure 4), the greatest number of participants is employed in energy planning roles $(23.4 \%)$, followed by R\&D (20.8\%), technical design (20.8\%), management (18.2\%), and business development (11.7\%). Administrative, legal, and authoritative (3.9\%) and other roles (1.3\%) are poorly represented.

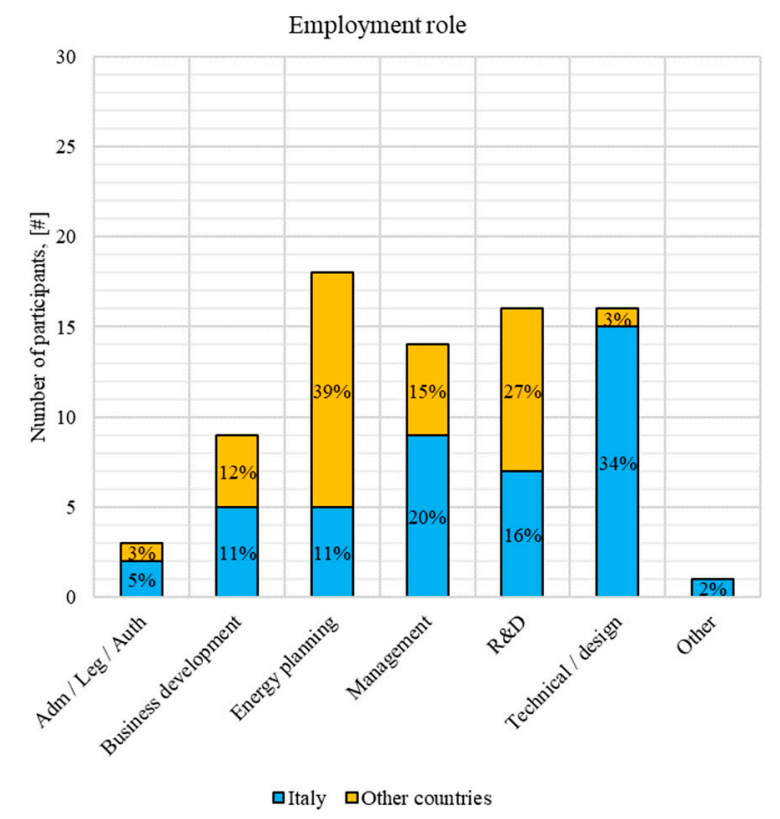

Figure 4. Number of survey participants as a function of the employment role.

Considering the role engaged for DH activities (Figure 5), differences appear with respect to the previous figure (Figure 4$)$. In particular, a decrease in managerial $(-6.5 \%), R \& D(1.3 \%)$, and development $(2.6 \%)$ positions is verified. On the other hand, an increase in technical $(+7.8 \%)$ and authoritative $(+1.3 \%)$ positions was found.

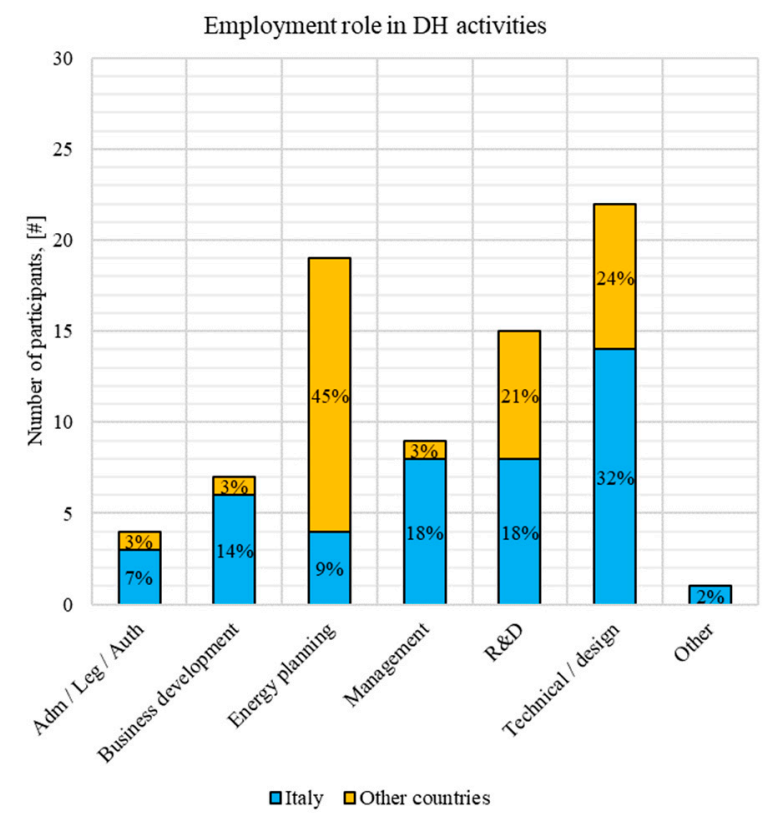

Figure 5. Number of survey participants as a function of the employment role engaged in DH activities. 
Regarding participants' experience (Figure 6), the main percentage of participants has more than 10 years of experience, followed by participants with experience between 5 and 10 years. Similarly low percentages are present for participants with lower experience.

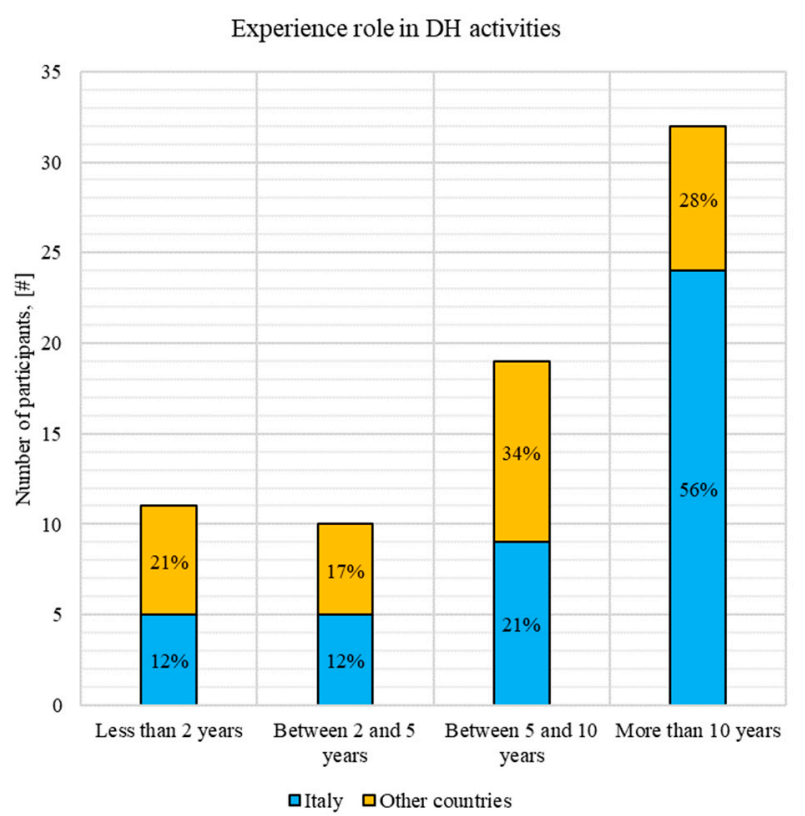

Figure 6. Number of survey participants as a function of experience in $\mathrm{DH}$ systems.

\subsection{The First Approach to the LTDH Concept}

The first approach of participants with the LTDH concept was analyzed, using the answers received in the second section. Only two Italian participants (4.5\%), employed in private companies respectively in managerial and energy planning roles for less than 2 years, did not know about the LTDH concept before participation in the survey (Table 2). Among those participants that knew of the LTDH concept, two did not complete the following questions, so they were not considered in the remaining part of the survey.

Table 2. Participants' knowledge of the LTDH concept before taking the survey.

\begin{tabular}{ccc}
\hline Is LTDH a Known Concept? & Italy & Other Countries \\
\hline Yes & 42 & 33 \\
\hline No & 2 & 0 \\
\hline
\end{tabular}

Regarding initial awareness of the LTDH concept (Figure 7), the greatest number of participants became aware of LTDH for the first time between 2010 and 2017. It is interesting to note that some participants answered "before 2000" through direct experience, leading to an apparent contradictions with the information available in the literature. Only one specified having proposed the innovative concept during a conference before 2000. Indeed, these answers can be justified by the fact that many participants consider all efforts to reduce the operative temperature as a LTDH implementation, even if only this characteristic (i.e., distribution temperature decreasing) is not sufficient to define a LTDH system, in accordance with [22,67]. 


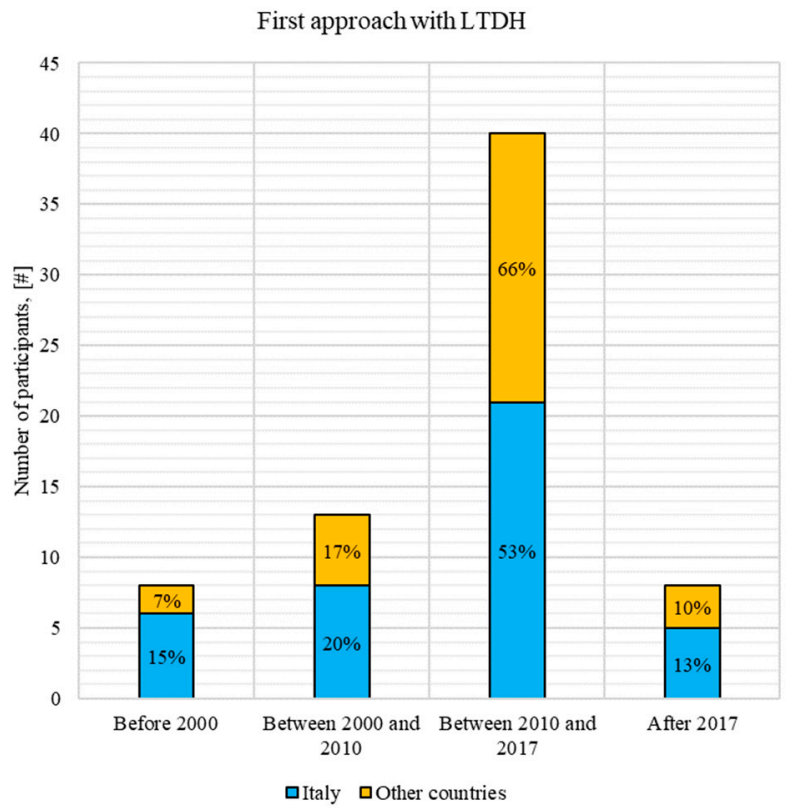

Figure 7. First exposure to the LTDH concept.

Thanks to the multi parametric approach, the influence of several parameters was investigated. Organizational influence is reported in Figure 8. As shown, maximum values are identified for between 2010 and 2017. Furthermore, the greatest number of participants that became aware of the LTDH concept before 2000 are employed in public and private companies. For those participants employed in universities, initial research activities started before 2010, while an exponential increase occurred after 2010 in accordance with the literature (papers, conferences, and workshop presentations).

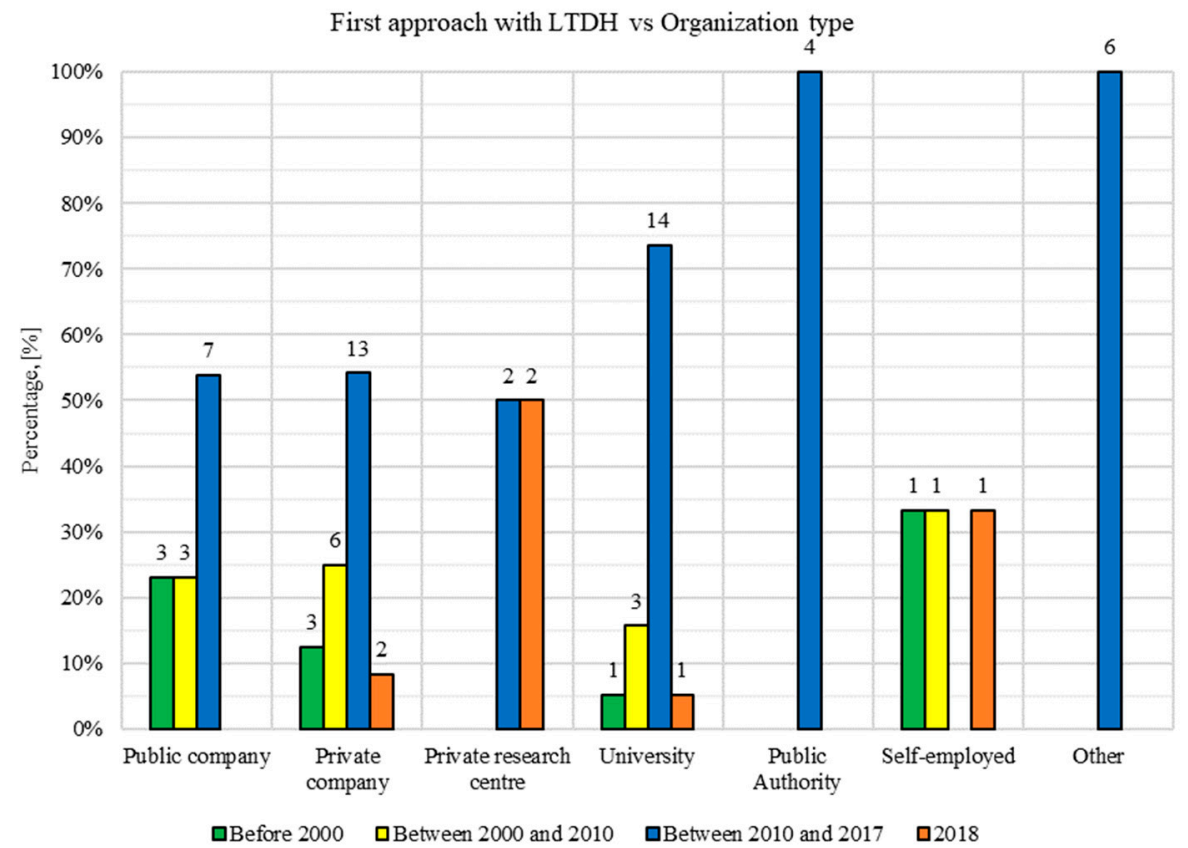

Figure 8. First exposure to the LTDH concept as a function of the organization in which participants are employed.

Concerning the role within the organization (Figure 9), as expected, those roles that are involved in the development of the company or in research were the first to become aware of LTDH. It is interesting to note that the greatest percentages of participants that became aware of LTDH before 2000 come 
from technical/design roles. However, because of the drop between 2000 and 2010, some doubts on LTDH definition is present. For research and development (R\&D), energy planning, and business development, an increasing trend appears during all the identified periods.

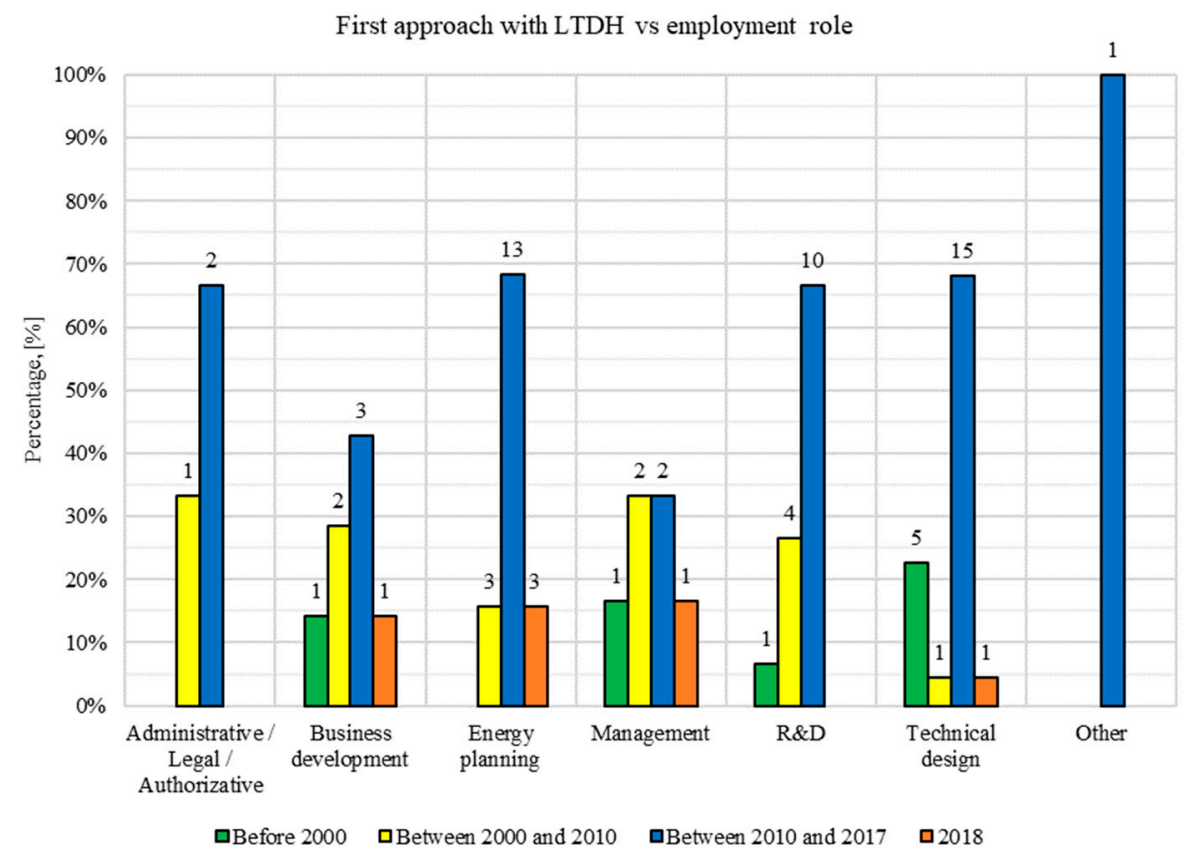

Figure 9. First exposure to the LTDH concept as a function of the role of the survey participants.

Regarding the communication channels, no differences seem to be present as a function of participants' nationality (Figure 10). As shown, conferences/seminars/workshops are the best communication channels for sharing the positive outcomes of the technology to need-owners and to ensuring the greatest knowledge transfer. In addition, peer-reviewed papers also play an important role in the state-of-the-art updates, but they are not the preferred channels for those who have to implement technical solutions. This condition can be justified by the fact that the very high-quality scientific results required for publications are not usually available at the beginning of a new technology. More resources should instead be dedicated to improving the sharing potentials of technical magazines/newspapers, Internet sites, and plant visits, which are theoretically accessible to a greater number of interested stakeholders. In particular, plant visits should be stressed in order to show the positive potentials of different solutions and to validate their performances in terms of efficiency, availability, and reliability.

Many participants also indicated "other" kinds of communication channels. Based on a more in-depth analysis, participants indicated direct experience or brainstorm meetings within the organization as communication channels. In this case, it has to be noted that presumably the LTDH concept was simply identified as a solution ensuring the reduction of operative temperatures, neglecting other conditions. 


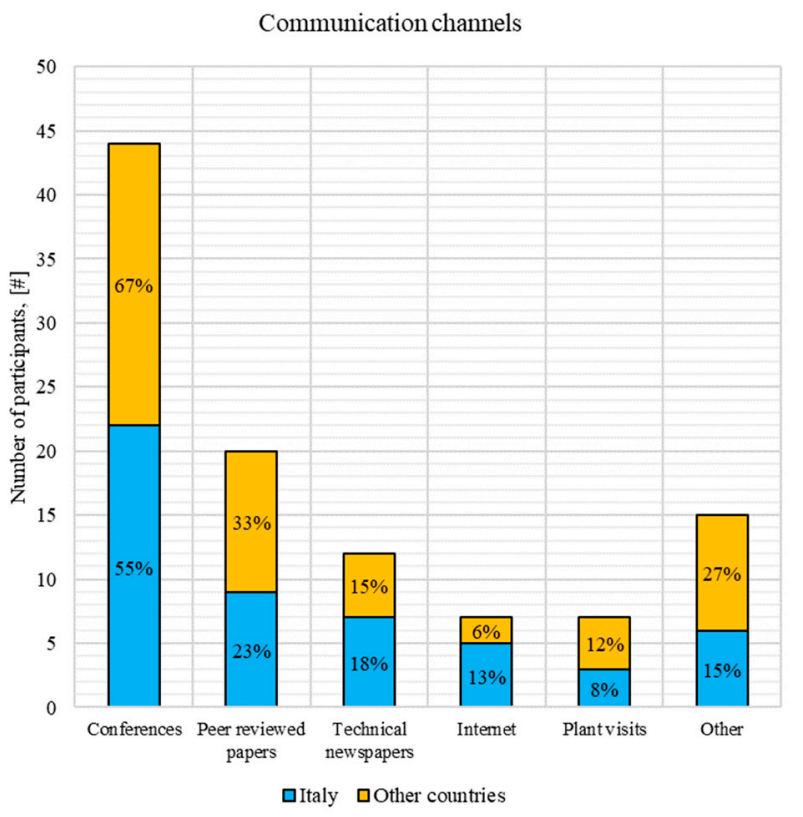

Figure 10. LTDH communication channels.

The influence of the organization type and of the employment role is shown (Figures 11 and 12). As expected, sector conferences were the preferred communication channel independently of the organization type or the role. Peer-reviewed papers contributed to knowledge-sharing between participants engaged in managerial roles, energy planning, and $R \& D$, while a very poor contribution appears for participants employed in technical roles, even though they are responsible for the design of new plants. Because of the low number of participants, the identification of statistical considerations for other roles is challenging.

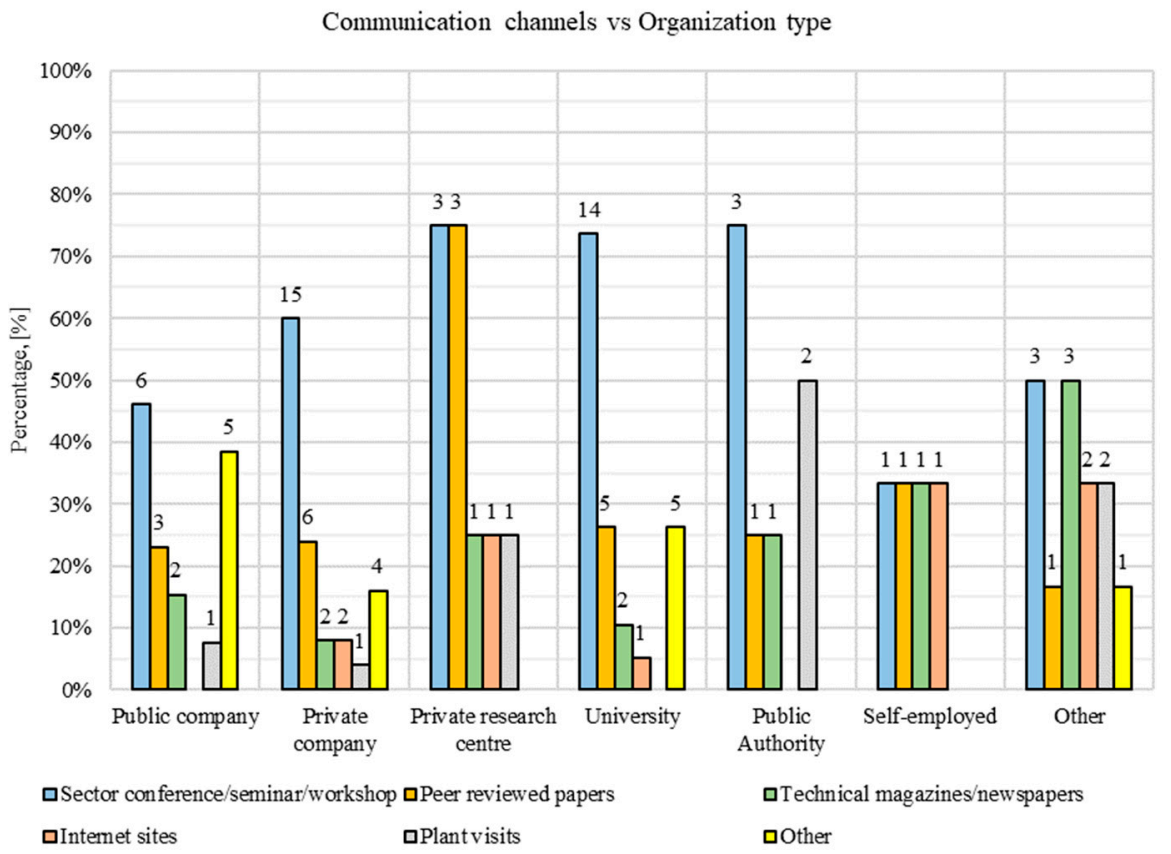

Figure 11. Communication channels as a function of the organization type. 


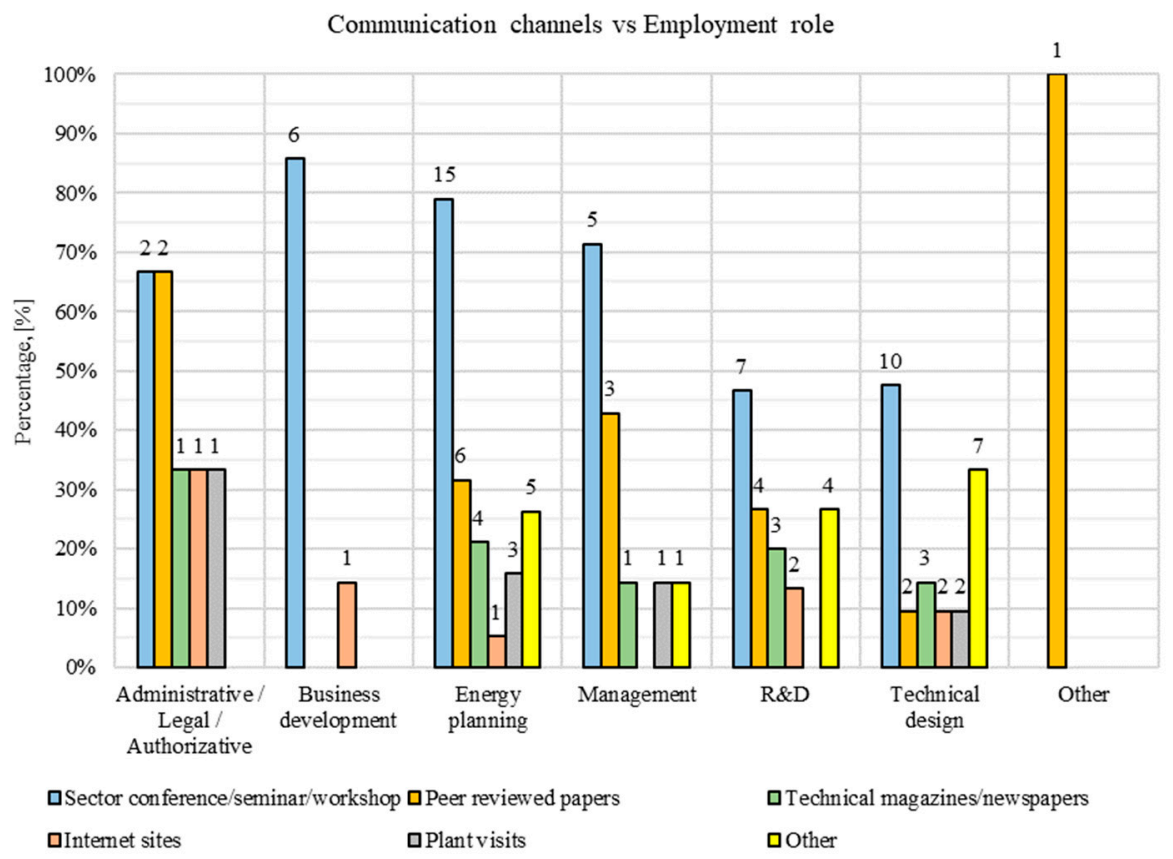

Figure 12. Communication channels as a function of the role within the organization.

3.3. Experts' Opinions about Traditional DH Systems: Strengths and Weaknesses with Respect to Individual Heating Systems

The advantages of traditional DH systems with respect to individual heating systems are reported in Figure 13. Despite the different nationalities, similar trends appear. In particular, the higher efficiency of DH systems is considered the greatest advantage by $65 \%$ of the participants, independently of the countries. The reliability of $\mathrm{DH}$ solutions is considered another point of force by almost $45 \%$ of the participants. Furthermore, there were different opinions from Italian and other participants about the ability to supply new and existing buildings. Participants also stated the ability to diversify input energy sources and the ability to supply several and different heating demands to ensure the highest performances as advantages.

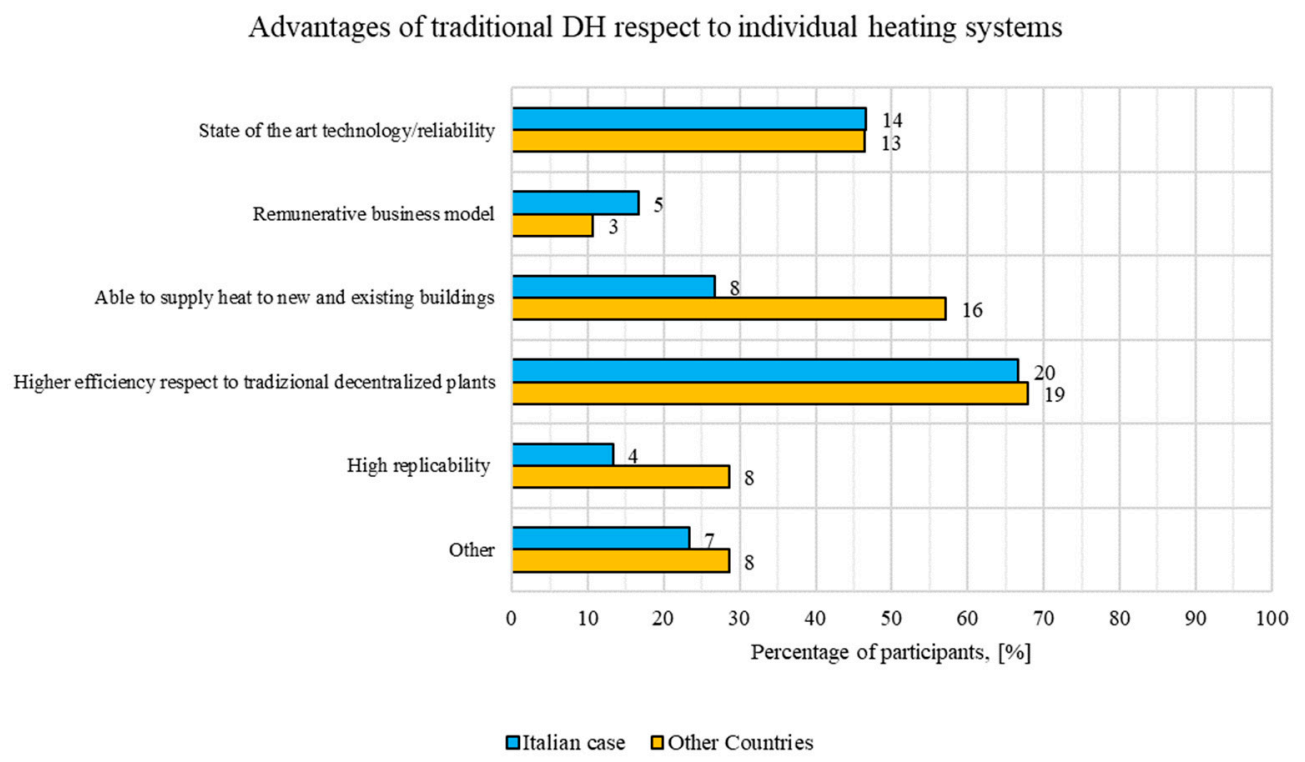

Figure 13. Advantages of traditional DH systems with respect to individual heating systems. 
The influence of organization, role, and experience is reported, respectively, in Figures 14-16. In all cases, all the participants agree to the fact that the higher efficiency of DH systems is the most important advantage, even if some differences are present. In particular, for public company employers, the reliability of the technology $(72.7 \%)$ has to be considered as a predominant advantage. Private company and university participants, while agreeing to the higher efficiency (61.1 and 68.8\%, respectively), attribute very lower importance to $\mathrm{DH}$ system reliability.

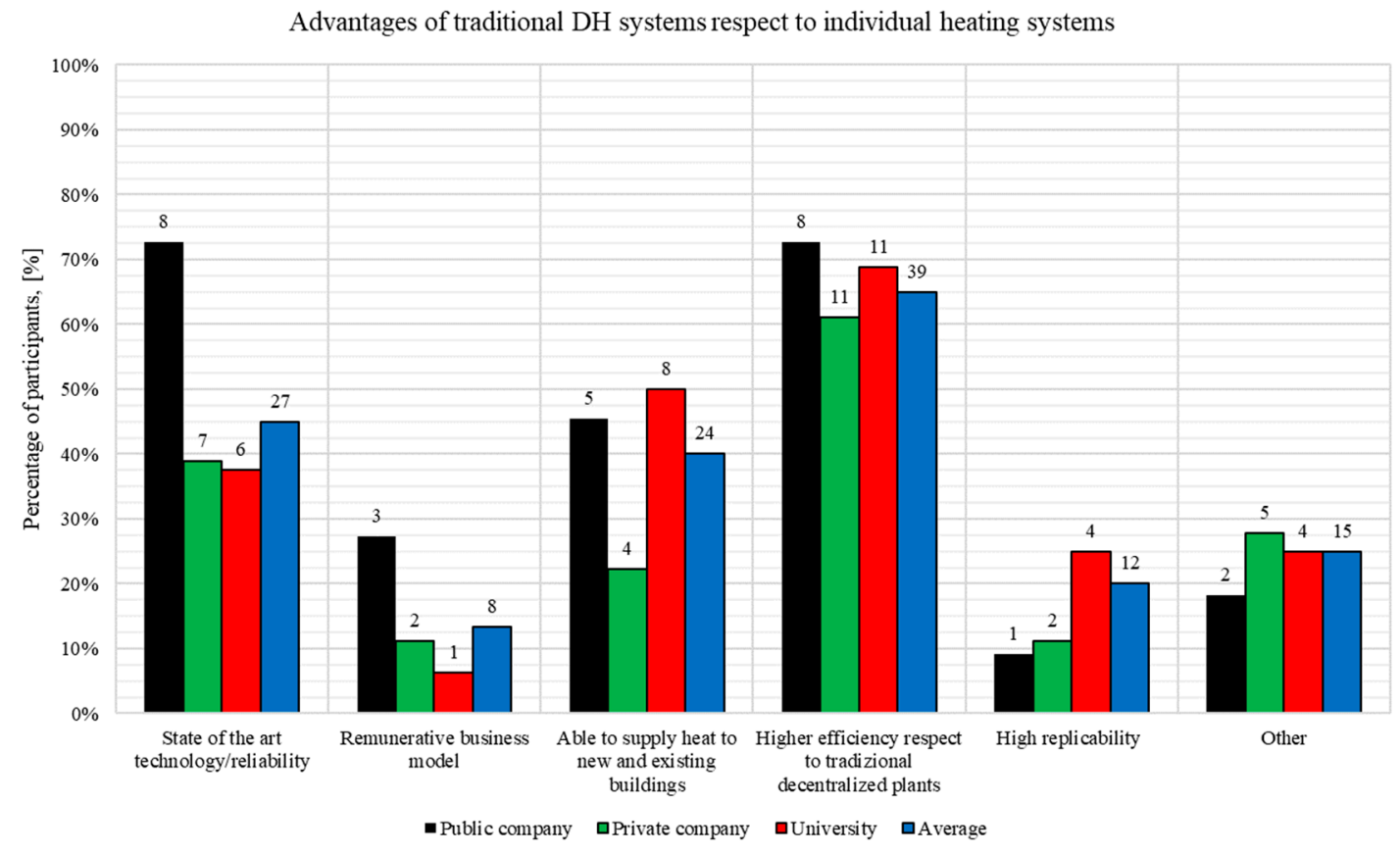

Figure 14. Advantages of traditional DH systems with respect to individual heating systems as a function of the organization type.

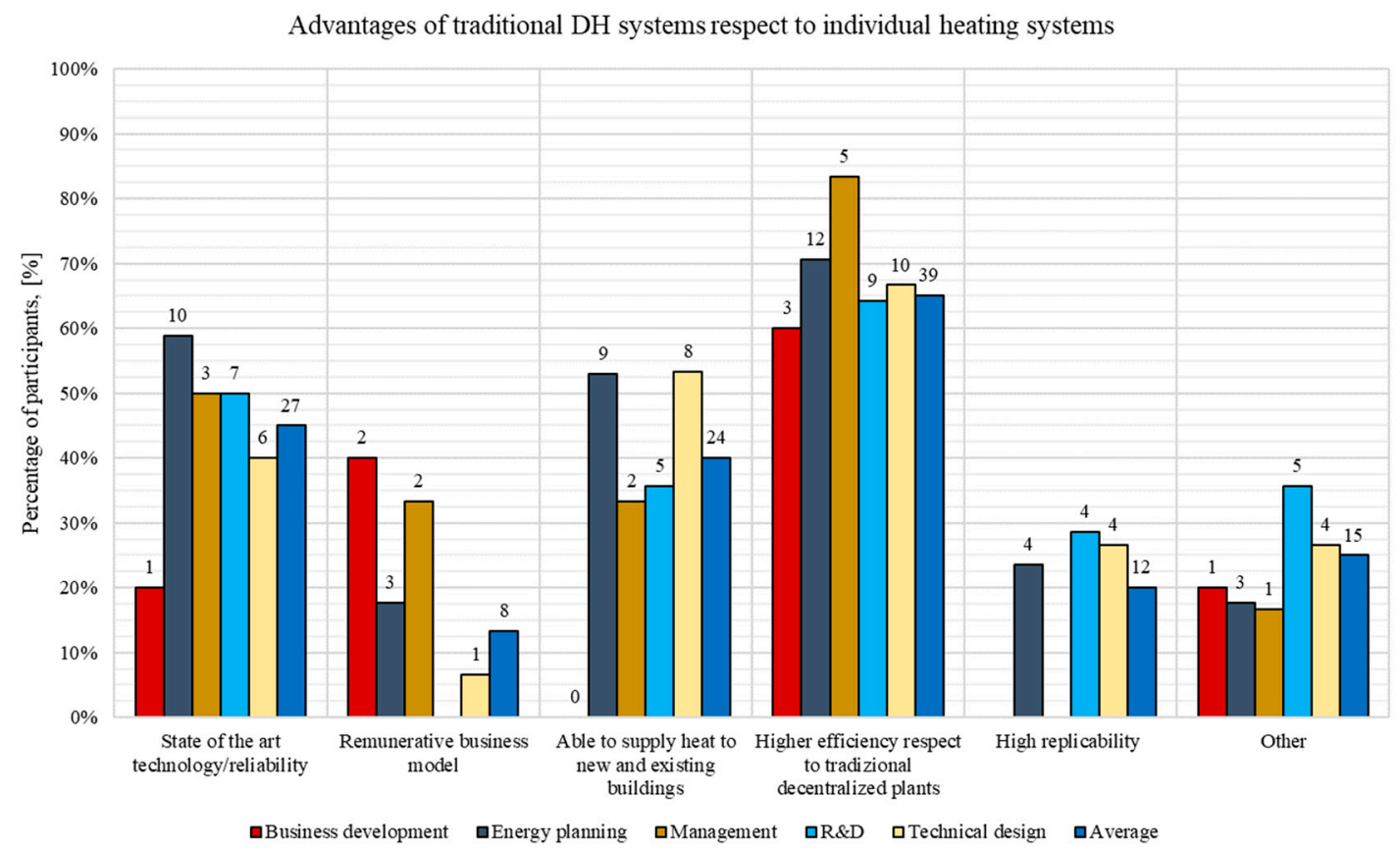

Figure 15. Advantages of traditional DH systems with respect to individual heating systems as a function of the employment role. 


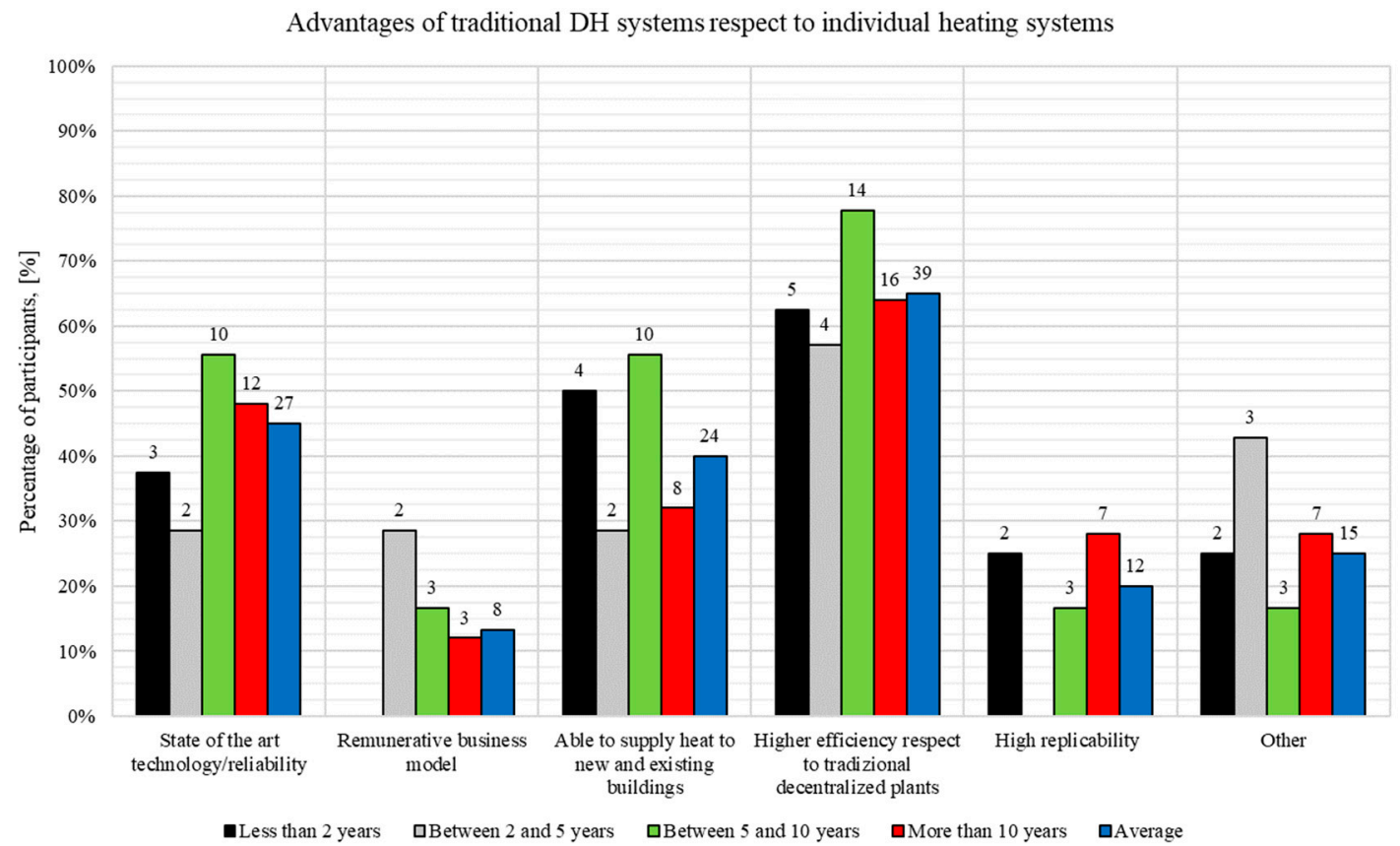

Figure 16. Advantages of traditional DH systems with respect to individual heating systems as a function of the experience.

Concerning the role, different opinions were found. After efficiency considerations, the business developers indicated the profitability of the existing business model (40.0\%), while energy planners, managers, and R\&D employers recognized reliability as the second-most important advantage (58.8, 50.0 , and $50.0 \%$, respectively). Technical participants valued the ability to heat supply new and existing buildings (53.3\%). No particular trend appears as a function of the participants' working experience.

Concerning disadvantages, as shown in Figure 17, distribution heat losses are considered the most important disadvantages with respect to individual heating systems, even though a greater importance seems to be given by the participants of other countries $(71.4 \%)$ than by the Italian participants $(40 \%)$. After this, the complexity to integrate renewable energy production within the central plant is indicated by participants from other countries $(42.9 \%)$. For the Italian case, the influence of several parameters on plant profitability represents the second most important disadvantage (33.3\%). In fact, since Italian DH plants mostly produce thermal and electric energy through CHP plants, the profit depends on several factors that cannot be controlled by DH operators, such as the electricity selling price. Despite this difference, similar responses are obtained demonstrating that traditional DH system represents state-of-the-art technologies for which similar conclusions can be made by experts of all sectors worldwide. Participants recognized other disadvantages that were not listed in the survey, such as the initial investment that is required for the implementation and that has to be overseen by the DH operator, the authoritative processes required to design and build a new system, the requirements in terms of reliability in order to ensure high levels of supply services, and the constraints imposed by the authorities. 
Disadvantages of traditional $\mathrm{DH}$ respect to individual heating systems

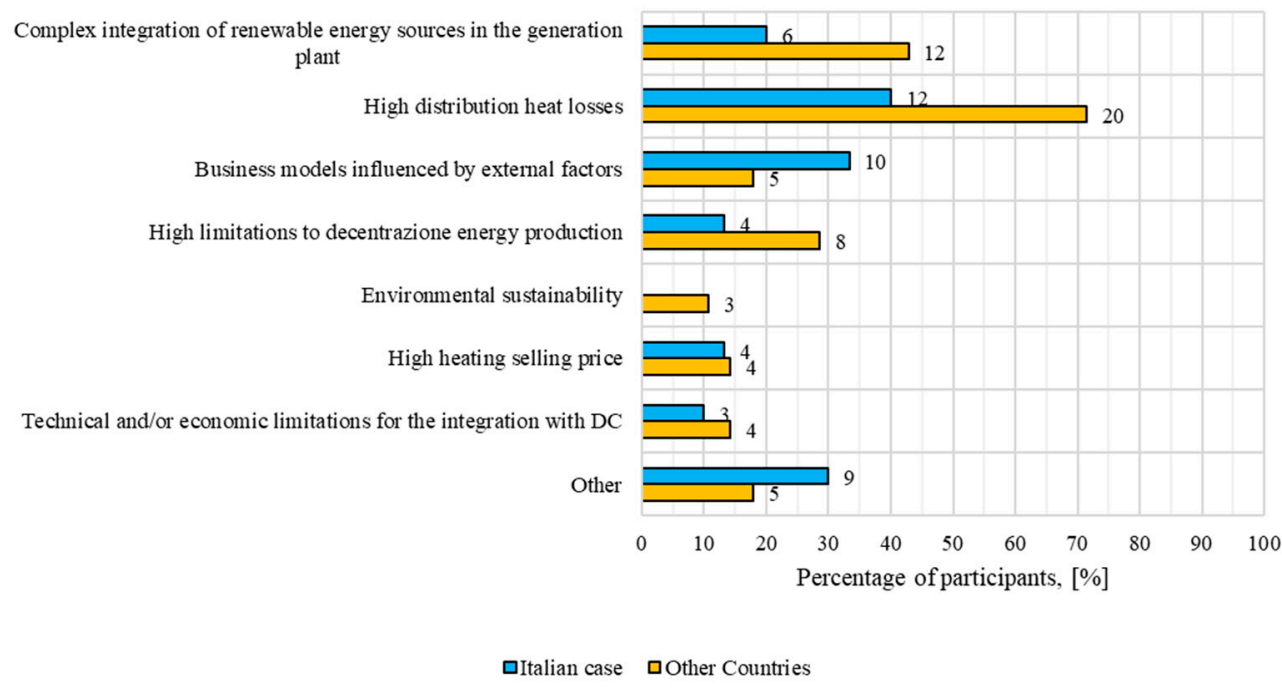

Figure 17. Disadvantages of traditional DH systems with respect to individual heating systems.

Furthermore, regarding disadvantages, answers were elaborated considering different parameters as reported in Figures 18-20. As shown in these three figures, few differences appear with respect to average values even if some deviations are present.

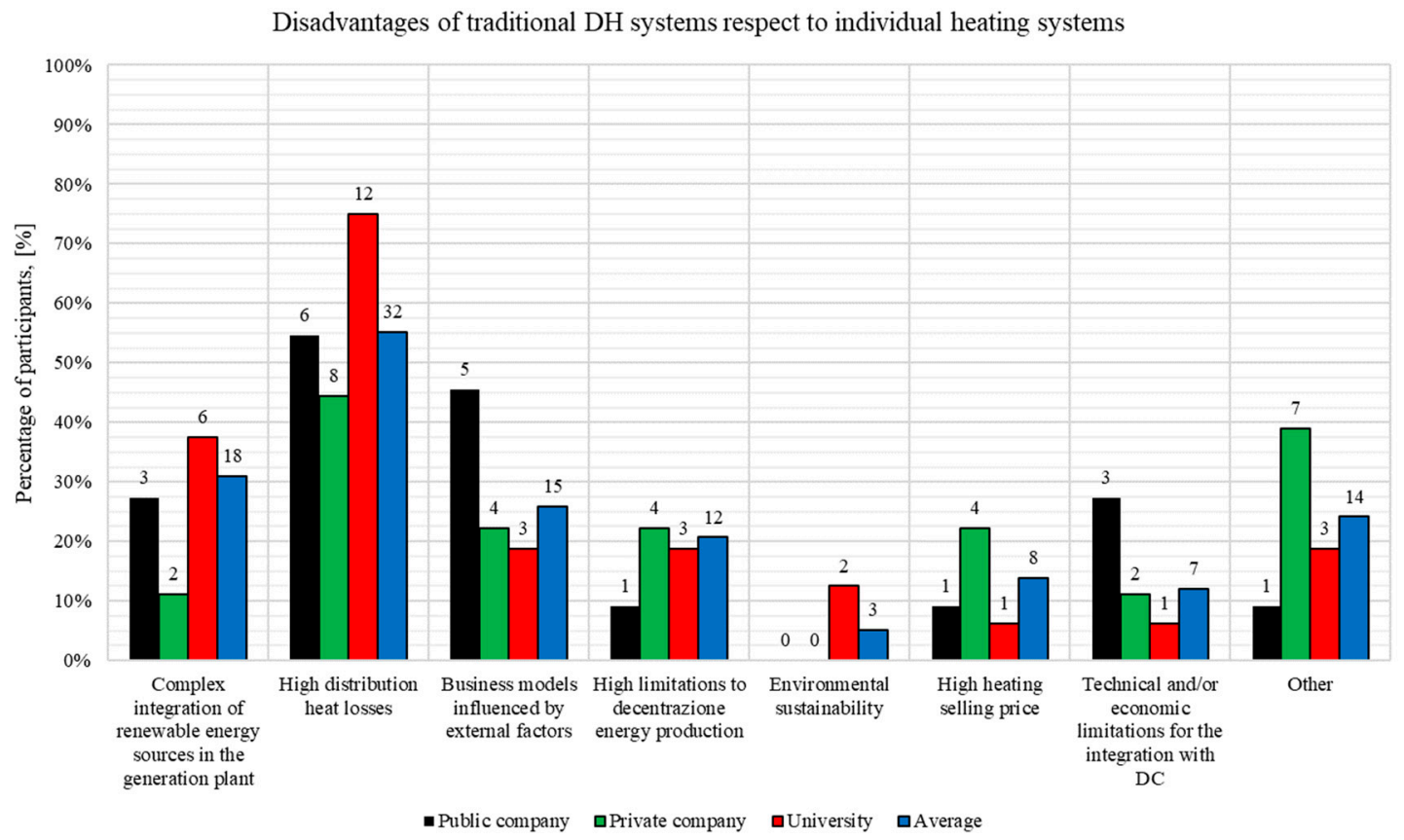

Figure 18. Disadvantages of traditional DH systems with respect to individual heating systems as a function of the organization type. 


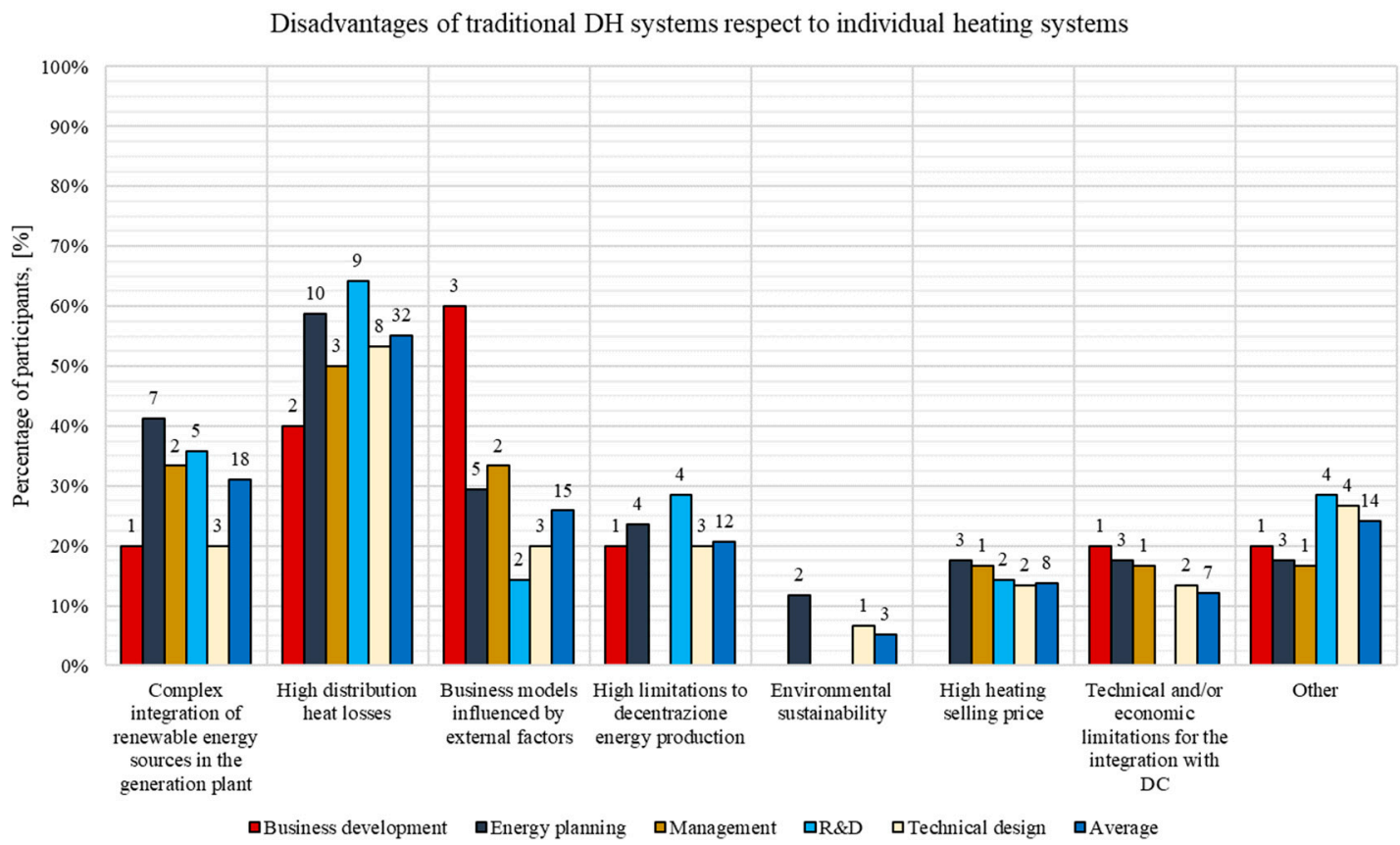

Figure 19. Disadvantages of traditional DH systems with respect to individual heating systems as a function of the employment role.

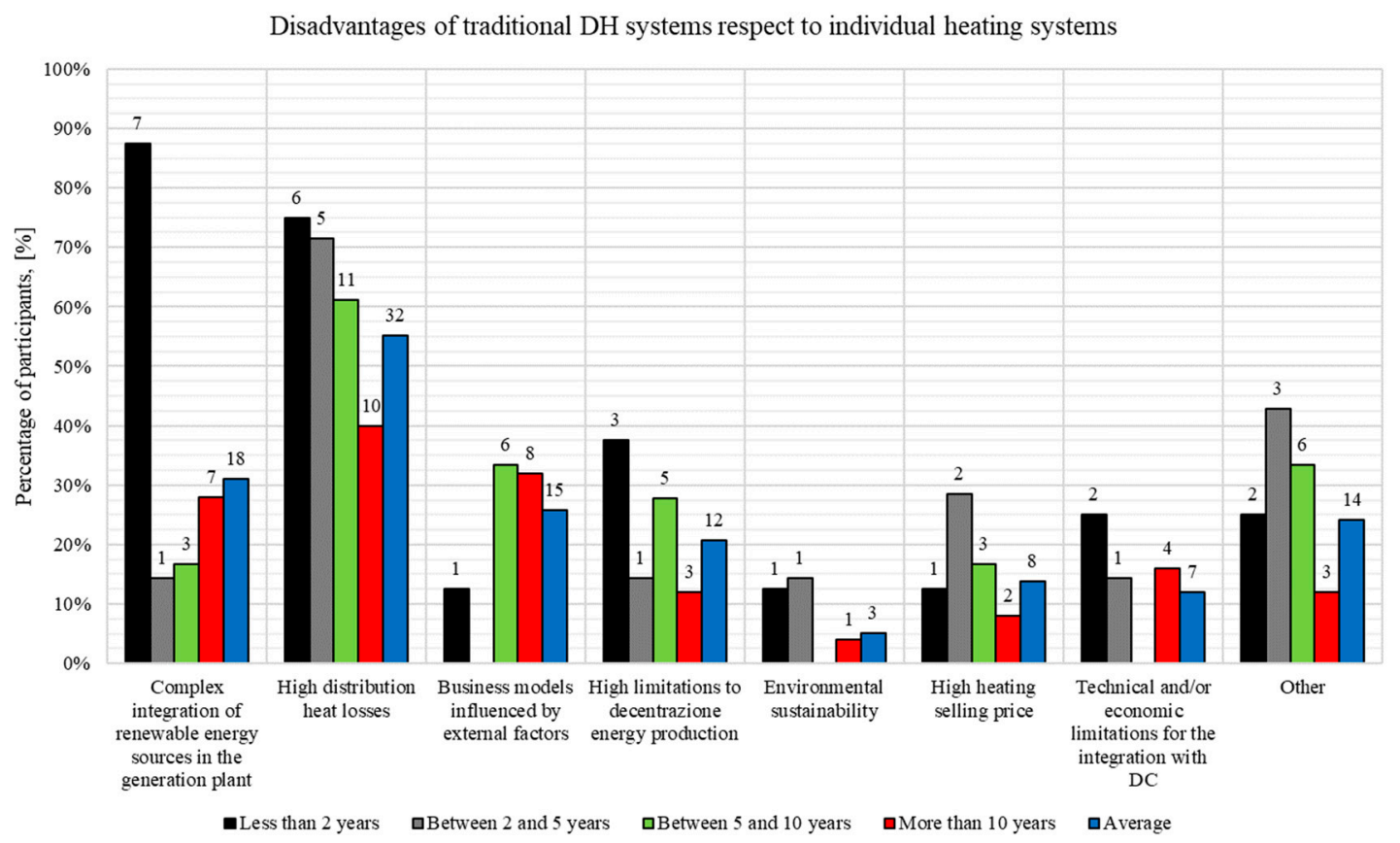

Figure 20. Disadvantages of traditional DH systems with respect to individual heating systems as a function of the experience.

Concerning the organization, public company participants believed that the most important disadvantage are the high distribution heat losses (54.5\%) followed by influence of external factors on the business models (45.5\%). For private company participants, after the high heat distribution losses $(44.0 \%)$, the second greatest disadvantage among the proposed ones are the high heat selling price $(22.2 \%)$ and the influence of external factors on business models $(22.2 \%)$. For participants that come from universities, the second greatest disadvantage after the high distribution heat losses $(75.0 \%)$ is the complexity to integrate the renewable sources in the generation plant $(37.5 \%)$. 
Regarding the employment role, not all the participants agree to the fact that the distribution heat losses are the main disadvantage. In fact, business developers indicated the influence of external factors on business models as the primary disadvantage $(60.0 \%)$. Other answers seem to be uninfluenced by the employment role.

Considering working experience, more deviations from average values appear as a function of the working experience. In particular, it seems that participants with low experience tend to recognize more disadvantages with respect to others.

\subsection{Experts' Opinions about LTDH Systems: Strengths and Weaknesses with Respect to Traditional DH Systems}

Similar results were found concerning the LTDH advantages with respect to different countries (Figure 21). Particularly, according to Figure 21 the ability to reduce operative thermal losses is the most important advantages (73.3 and $82.1 \%$ ) followed by the lower complexity of integrating renewable sources at generation plants (50.0 and $64.3 \%$ ). More importance is given by participants outside Italy to the ability to increase system energy efficiency $(75.0 \mathrm{vs.} 33.0 \%)$ thanks to a greater utilization of renewables. Operative cost reduction does not appear to be a primary advantage for Italians or participants from other countries (30.0 and 32.1\%). In fact, additional operative costs could be required to power supply remote temperature boosters in LTDH networks.

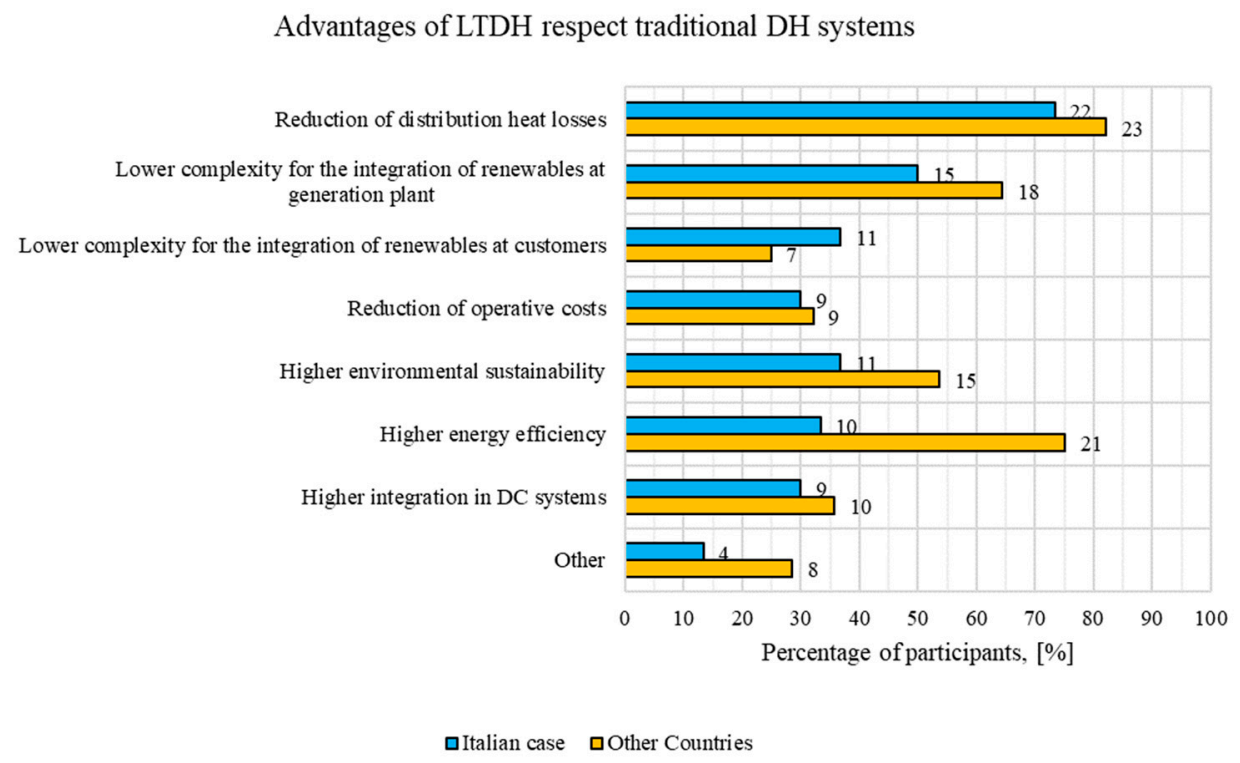

Figure 21. Advantages of LTDH with respect to traditional DH systems.

The evaluations of answers as a function of organization type, employment role, and working experience are illustrated in Figures 22-24.

Considering the organization type, few differences appear with respect to the average values for renewable integration, environment sustainability, and energy efficiency. In particular, little attention to environment topics seems to be given by public and private company employers. 


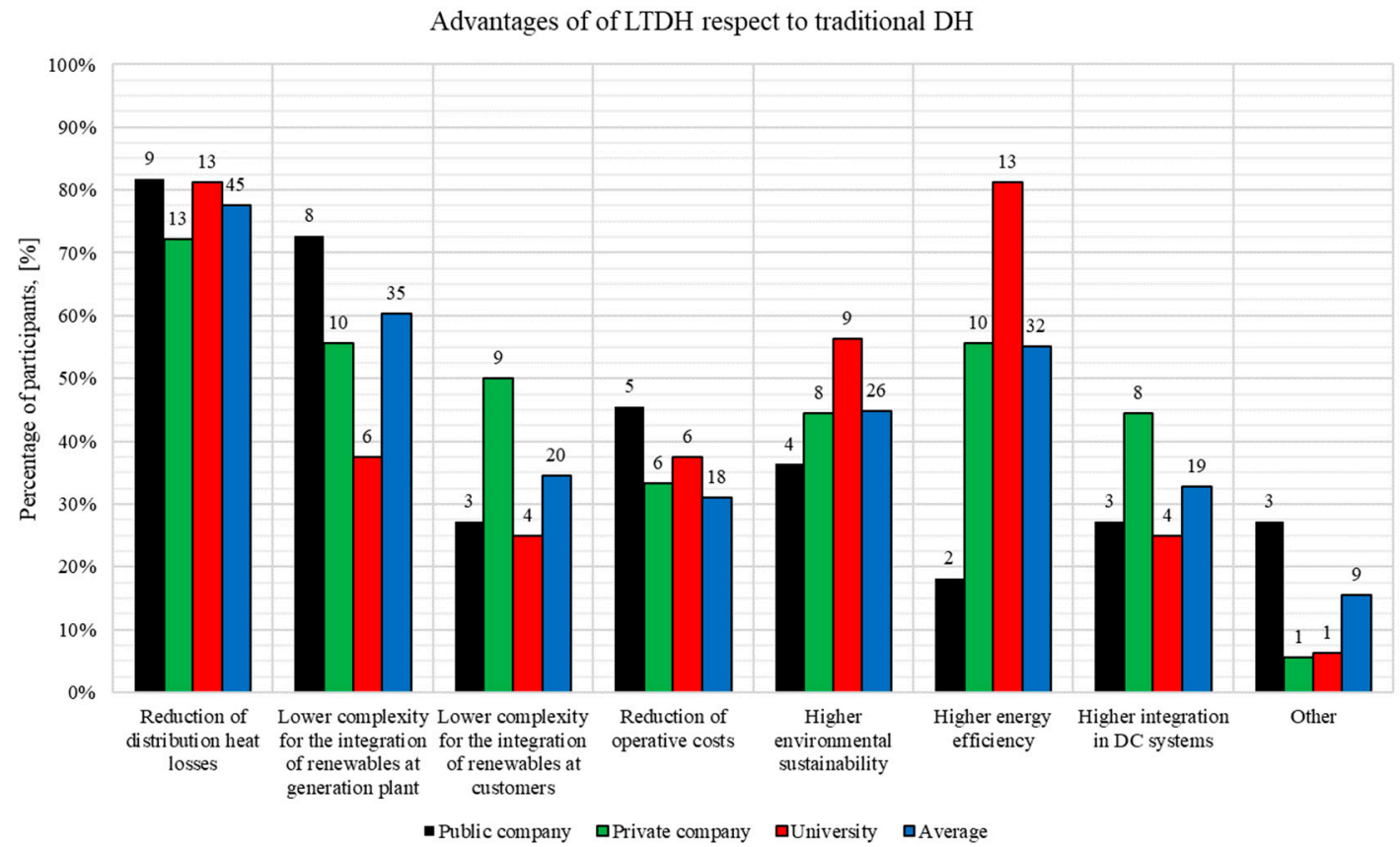

Figure 22. Advantages of LTDH systems with respect to traditional DH as a function of the organization type.

Furthermore, regarding the employment role, few differences are present. In particular, participants involved in technical roles and R\&D mostly appreciate the reduction of complexity to integrate renewables, while little importance is given by business developers, energy planners and managers. Evaluating economic aspects, business developers and managers give more importance to the reduction of operative costs. Energy planners, $R \& D$, and technical employers pay more attention to the sustainability and energy efficiency topics.

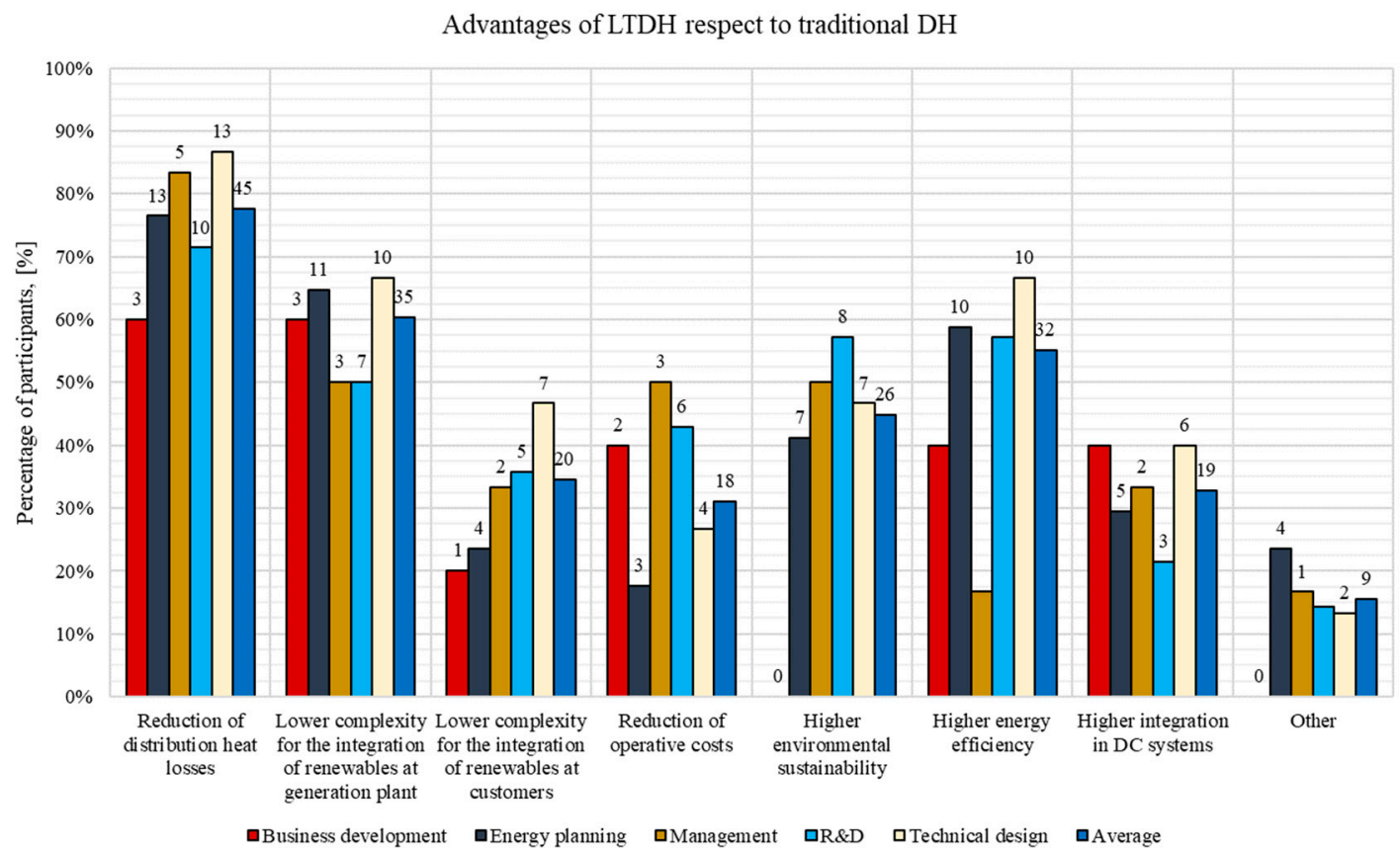

Figure 23. Advantages of LTDH systems with respect to traditional DH as a function of the organization type. 
Considering working experience, participants with little working experience give greater importance to energy efficiency topics with respect to economic aspects. However, apart from these participants, negligible differences with respect to average values were found.

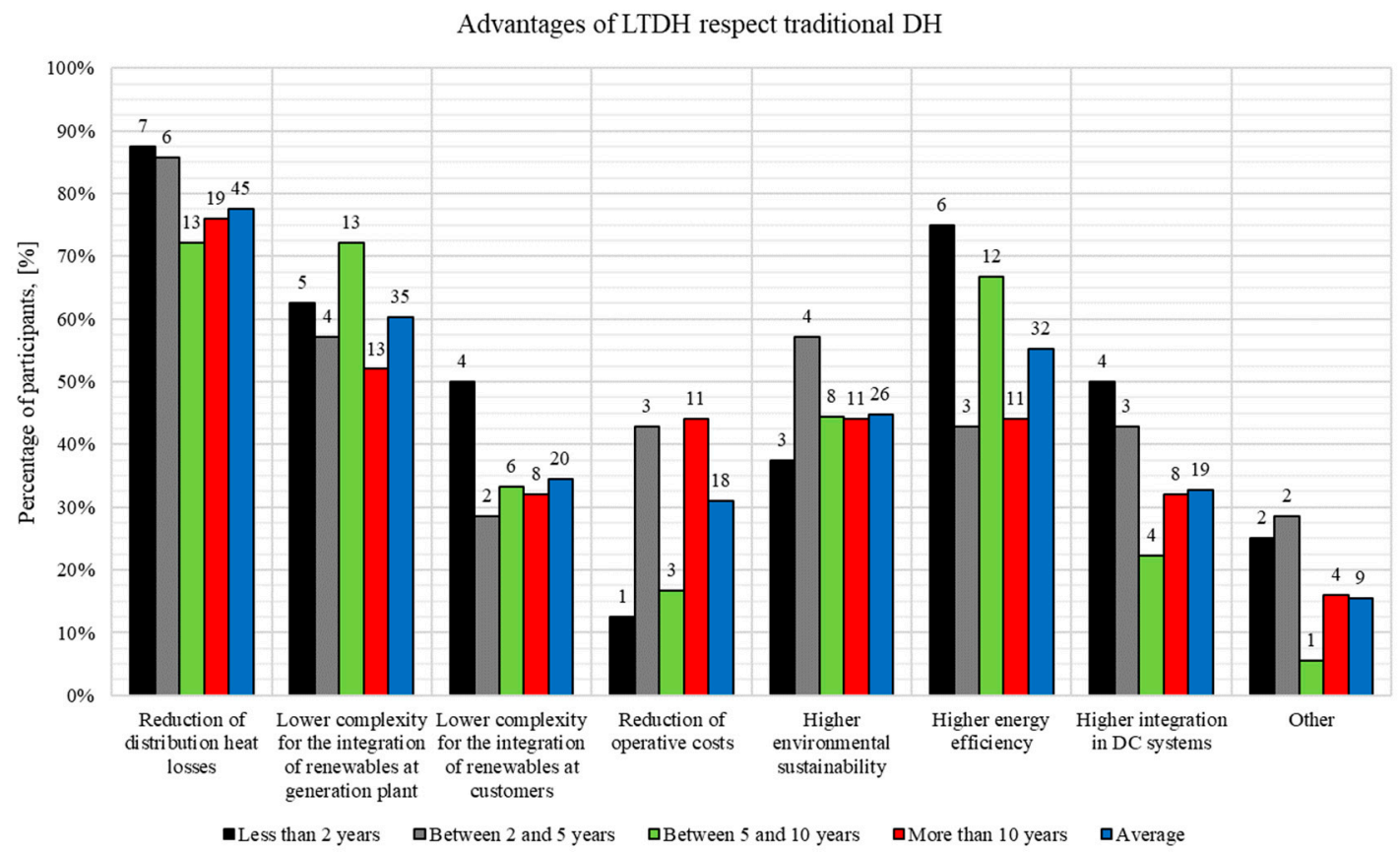

Figure 24. Advantages of LTDH systems with respect to traditional DH as a function of the experience.

Concerning disadvantages, the need to locally boost the supply temperature in order to satisfy customers' heating and hot water sanitation demands is the most significant for all participants. With attention to DHW production, dedicated solutions, consisting, for example, in thermal or chemical strategies, have to be implemented in order to avoid legionella proliferation in water storage [36]. As shown below (Figure 25), Italian experts agree to the fact that a business model is still required for LTDH. In fact, since a bidirectional flow of energy to and from DH networks is expected, new actors, i.e., the prosumers, will appear in the market requiring dedicated regulations and legislative initiatives able to identify how to monetize the energy fluxes. Differently from Italian participants, other participants recognized the complexity required to manage the overall system. As expected, in fact, the presence of remote energy sources requires additional efforts and resources and new control strategies to avoid thermal and hydraulic imbalances within the networks. However, the need to monitor energy fluxes to and from the networks, i.e., the smart metering implementation, is considered a disadvantage by few experts. Other participants proposed higher operative costs due to the electrical consumption required to supply power for temperature boosters at the substations, and the need to convince customers to apply new technical solutions to be integrated with the LTDH solution. 


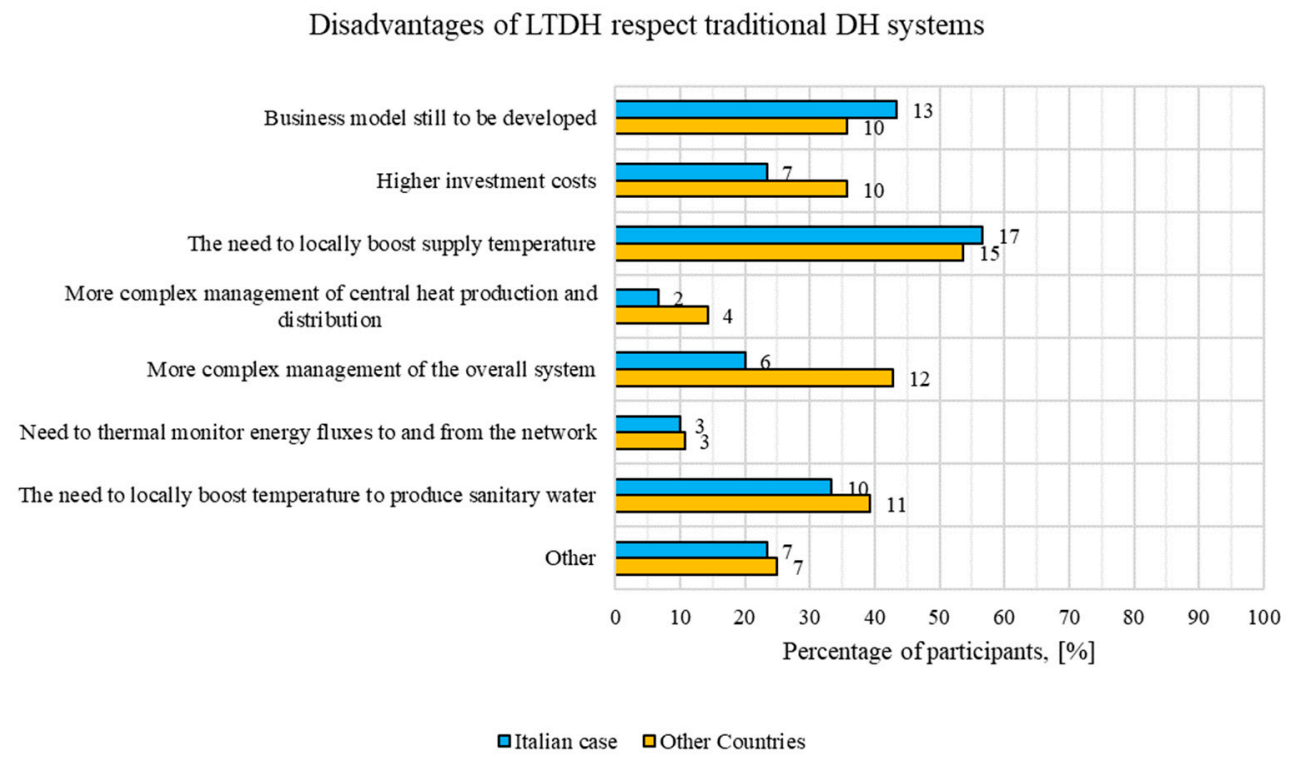

Figure 25. Disadvantages of LTDH systems with respect to traditional DH systems.

Considering the organization type (Figure 26), it seems that participants employed in private companies greatly evaluated the disadvantages arising from LTDH implementation. In addition, it should be noted that system complexity is mainly considered by those participants employed in universities.

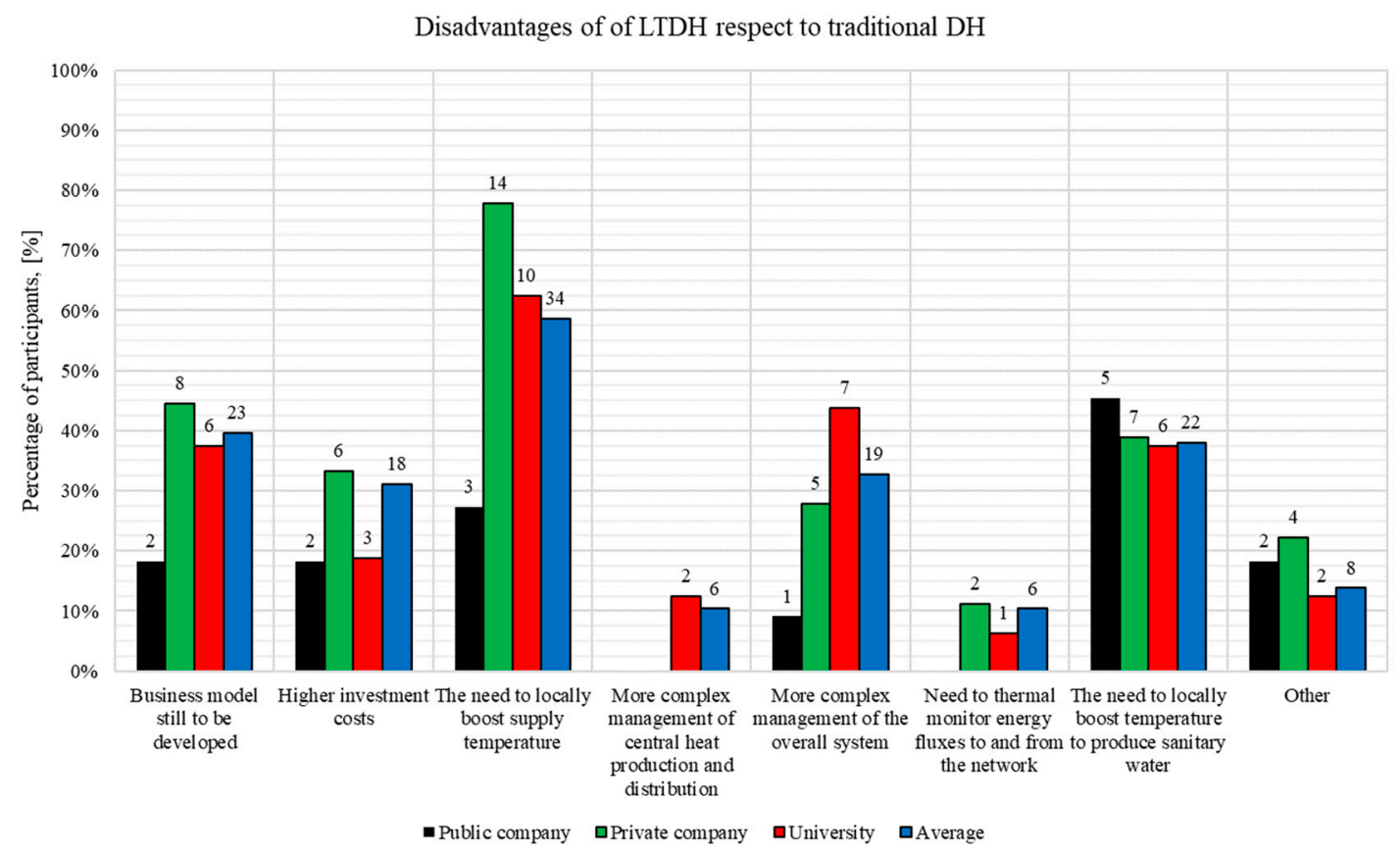

Figure 26. Disadvantages of LTDH systems with respect to traditional DH as a function of the organization type.

In Figure 27, role influence is shown. As expected, the need to locally supply the temperature for heating and HSW demands is considered the main disadvantage, independently of the role, even if differences in the percentage are present. With respect to average values, differences in participants' opinions about the economic investment and the complexity to manage the overall system are also present. In fact, an underestimation by business developers, energy planners, and mangers is present with respect to average values. 


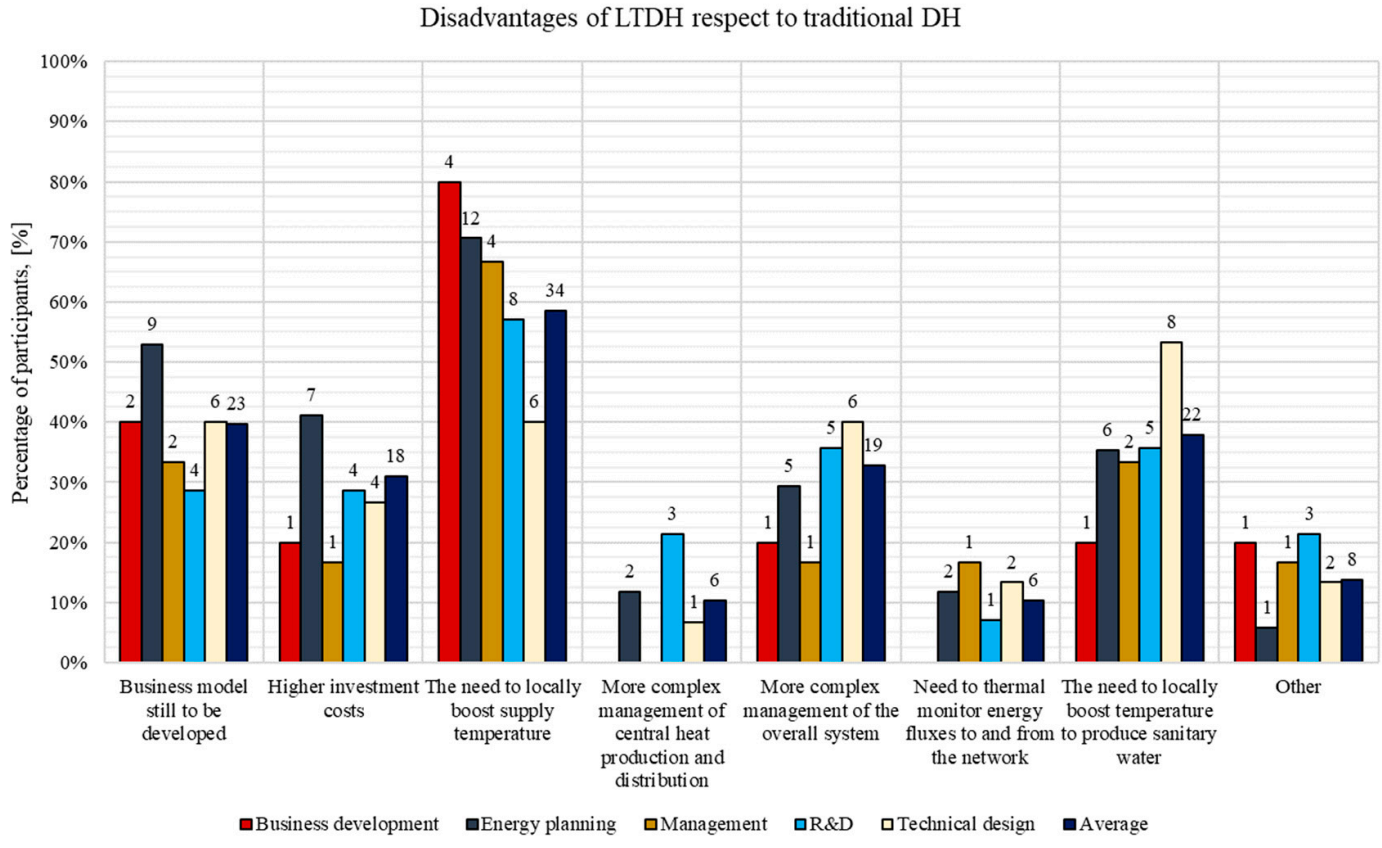

Figure 27. Disadvantages of LTDH systems with respect to traditional DH as a function of the employment role.

In Figure 28, working experience is considered. In particular, it appears that, for participants with experience less than 2 years, the main disadvantage is the absence of a ready business model in which LTDH can be developed. In addition to this, it has to be noted that these participants do not consider the need to locally boost the temperature to produce hot, sanitary water as a disadvantage, in contrast with the other participants. For participants with experience between 2 and 5 years, three issues are considered the most important disadvantages of LTDH with respect to traditional systems: the need to develop a dedicated business model, the high investment costs, and the need to locally boost the supply temperature. For those participants with experience greater than 5 and 10 years, the main disadvantage is the need to locally boost the supply temperature for heating and HSW purposes.

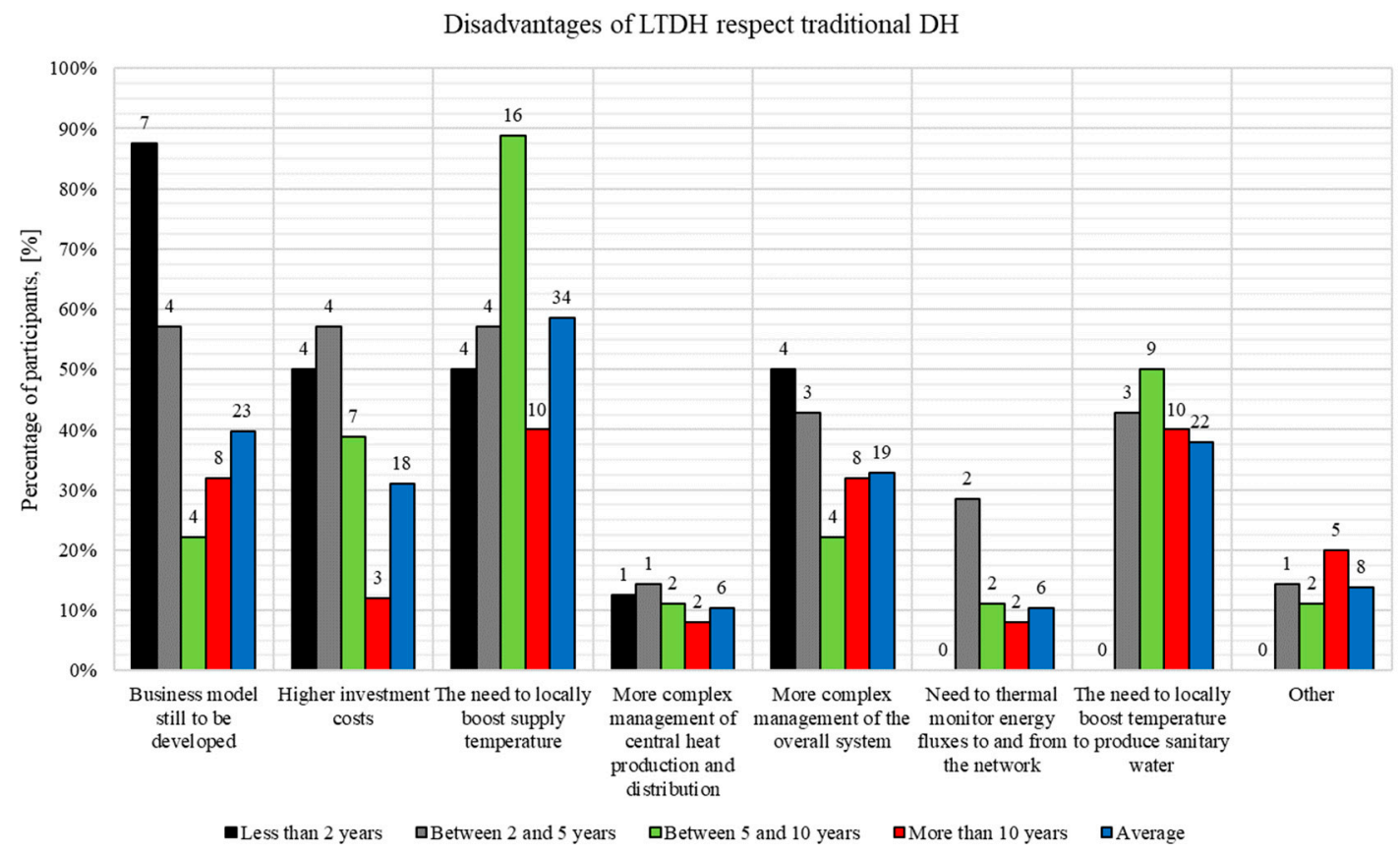

Figure 28. Disadvantages of LTDH systems with respect to traditional DH as a function of the experience. 
3.5. Experts' Opinions about LTDH Systems: What Is the Importance of the Proposed Barriers with Respect to the Implementation of the LTDH Concept

Experts' opinions about existing barriers with respect to the implementation of LTDH resulted in similar trends independently of the country, as shown in Figure 29. Few differences, in fact, are present. In the Italian case, the possible "high investment cost" (B1) is considered the most critical barrier, followed by "the limited opportunities for existing substation retrofitting" (B6) and "the need to locally boost supply temperature" (B2). Even if the same three barriers are the most concerning for experts outside Italian borders, the greatest importance is given to (B2). Lower importance from all the participants is given to those barriers that involve the changes of the existing business with the need, for example, to introduce new rules, to change existing contracts, or to identify incentive actions ensuring the profitability of the new business. Among these barriers, the following can be cited: "the need to modify existing business models" (B3), "the contractual restrictions about supply temperature conditions" (B5), "the relationship with the customer" (B7), "the Legislative/Regulatory/Authorization constraints" (B8), and "the conflictual relationship between the grid operator, the district heating plant manager, and the eventual manager of the sub-station" (B9). Very low importance is given to "the metering of the thermal energy fluxes to and from the network" (B4), possibly because of the availability on the market of dedicated technologies for this purpose, such as smart meters. However, the greatest difference of opinion regards "the lack of the required technical competence" (B10), which assumes a very important role for the implementation of the LTDH concept outside Italy.

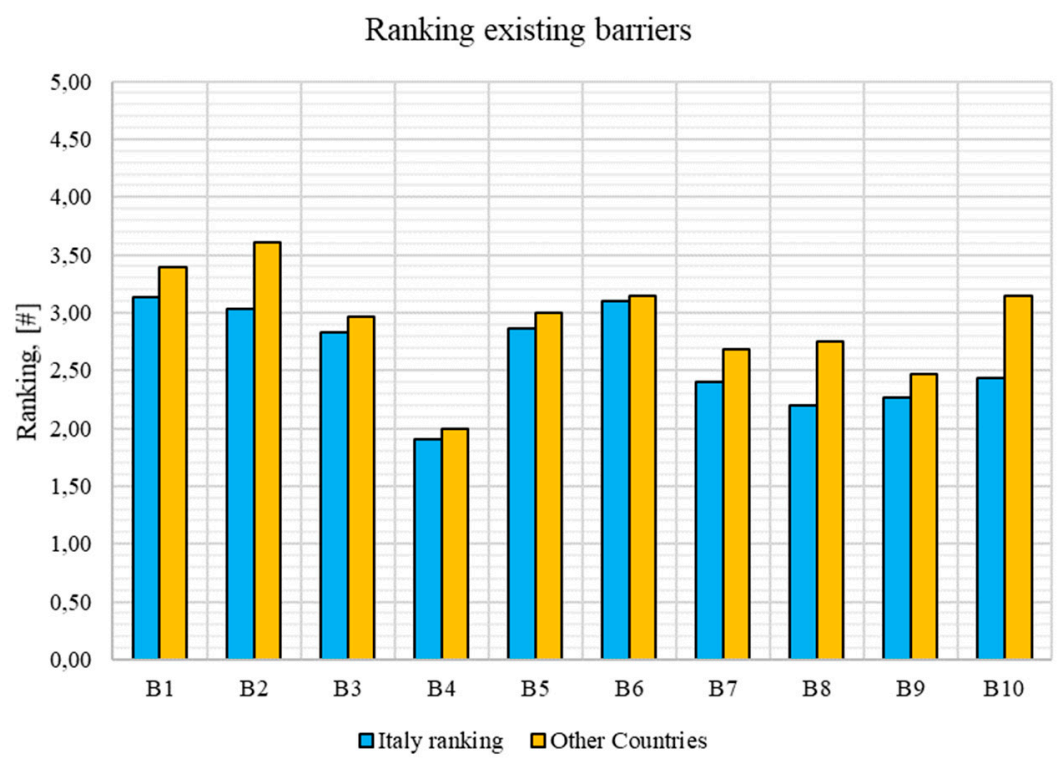

Figure 29. Ranking of the identified existing barriers against the implementation of the LTDH concept. (B1) High investment cost; (B2) the need to locally boost supply temperature; (B3) the need to modify existing business models; (B4) the metering of the thermal energy fluxes to and from the network; (B5) the contractual restrictions about supply temperature conditions; (B6) the limited opportunities for existing substation retrofitting; (B7) the relationship with the customer; (B8) the Legislative/Regulatory/Authorization constraints; (B9) the conflictual relationship between the grid operator, the district heating plant manager, and the eventual manager of the sub-station; (B10) the lack of the required technical competence.

Considering organization influence (Figure 30), few differences arise. In particular, public employers give a lower ranking to all barriers with respect to the average values, even if limited possibilities to retrofit existing DH substations and the need to modify existing business models are considered the most important barriers. For private company participants, the most important barrier is the high investment cost followed by the modification of existing business models. For participants 
from universities, the most important barriers are the need to modify the existing business models and the lack of the required technical competences.

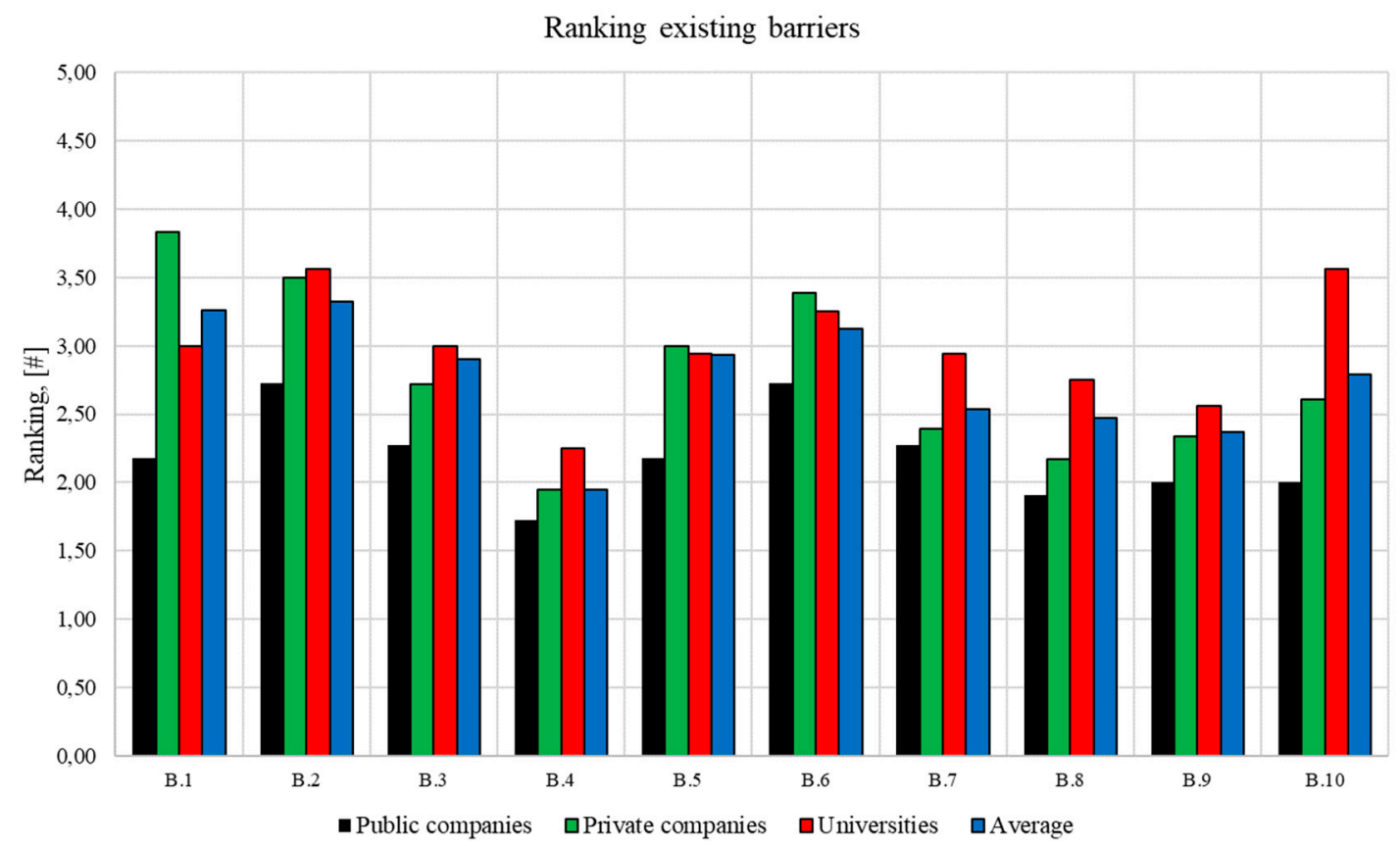

Figure 30. Ranking of the identified existing barriers as a function of the organization type.

Concerning the employment role (Figure 31), energy planners give, on average, the highest ranking to the barriers considering the high investment costs as the most important in accordance with managers. For business developers and R\&D specialists, the need to modify the existing business is the most significant barrier against LTDH implementation.

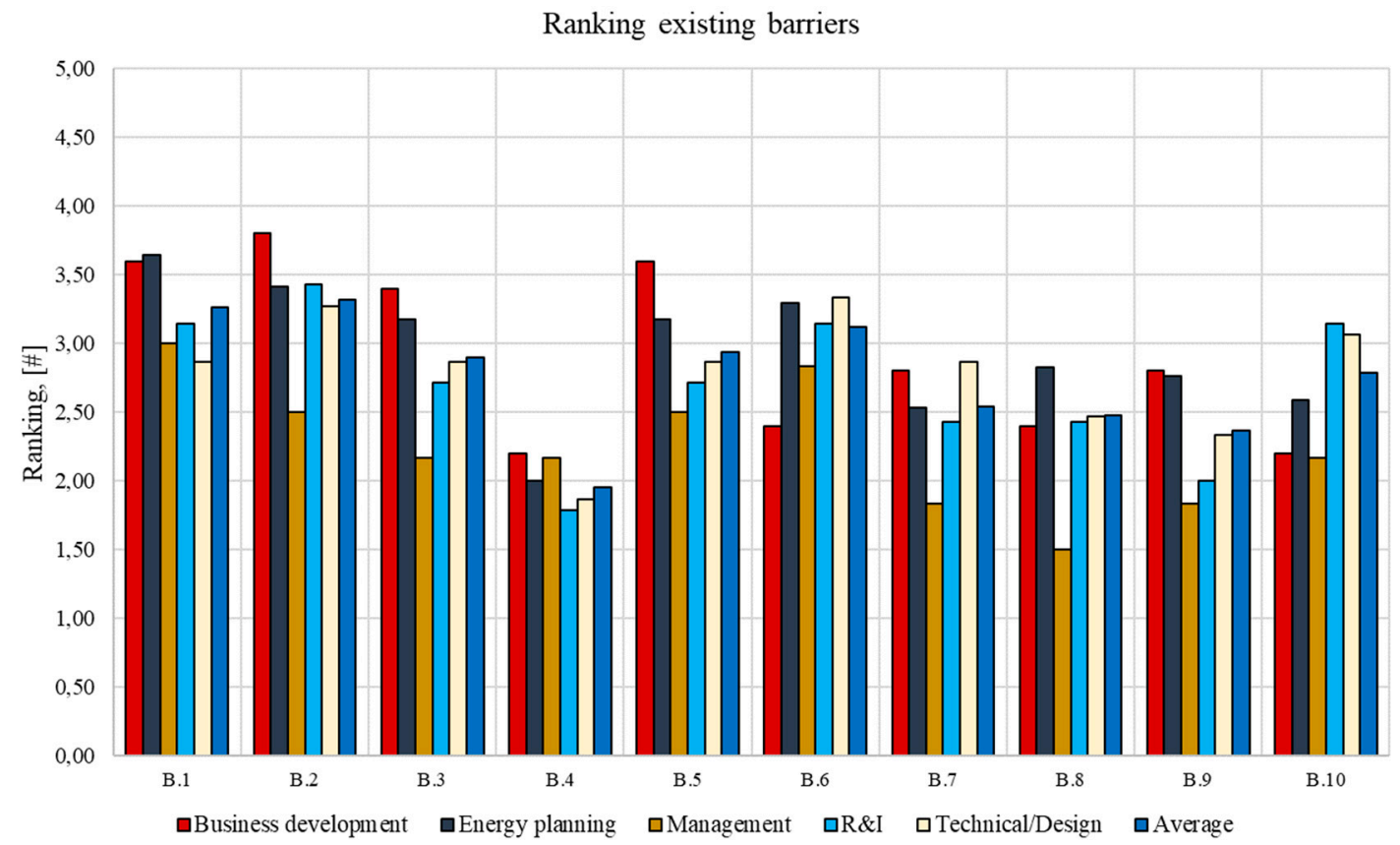

Figure 31. Ranking of the identified existing barriers as a function of the employment role. 
To conclude, in Figure 32, the influence of working experience is also reported. As shown, few deviations with respect to the average values are present except for some barriers (B.1, B.3, and B.5) where very high rankings were calculated considering the answers of those participants with less than 2 years of experience.

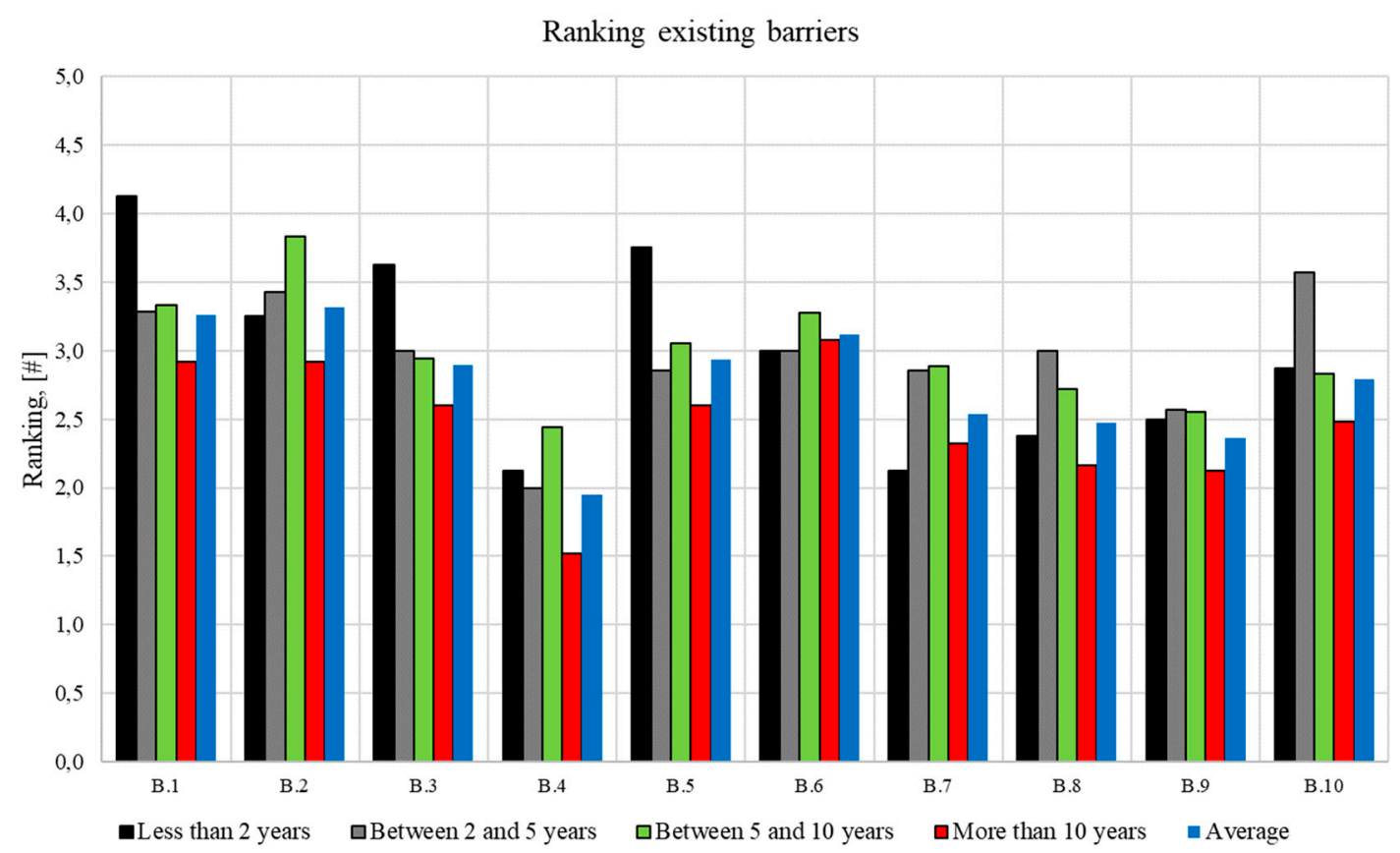

Figure 32. Ranking of the identified existing barriers as a function of the working experience.

\subsection{Experts' Opinions about the Diffusion of the LTDH Concept in Next Twenty Years}

In accordance with Figure 33, different opinions were given by Italians and other participants about LTDH market development in the next 20 years. In particular, a very low penetration is expected in the Italian market, where $60 \%$ of the experts thought that poor diffusion is the most probable development scenario. A lower percentage of experts believed that the LTDH concept would see good diffusion. Only one Italian participant stated that market penetration is already in place. A different perception is present outside Italian borders, where only a small percentage of the participants $(11.1 \%)$ thought that LTDH would not have a good diffusion in the market, while the most experts $(63.0 \%)$ supposed that the LTDH concept would see good diffusion. In this case, some experts believed that the business is already in place $(18.5 \%)$.

Considering organization influence (Figure 34), very different opinions about LTDH penetration in the market were found. While for public and private company participants poor diffusion will be present, for university participants, good diffusion is expected. A more complex situation appears considering the value obtained as a function of the employment role (Figure 35), so it is very difficult to perform a characterization. Finally, considering working experience (Figure 36), it seems that the good diffusion of LTDH is mainly expected by participants with less experience in the field. 


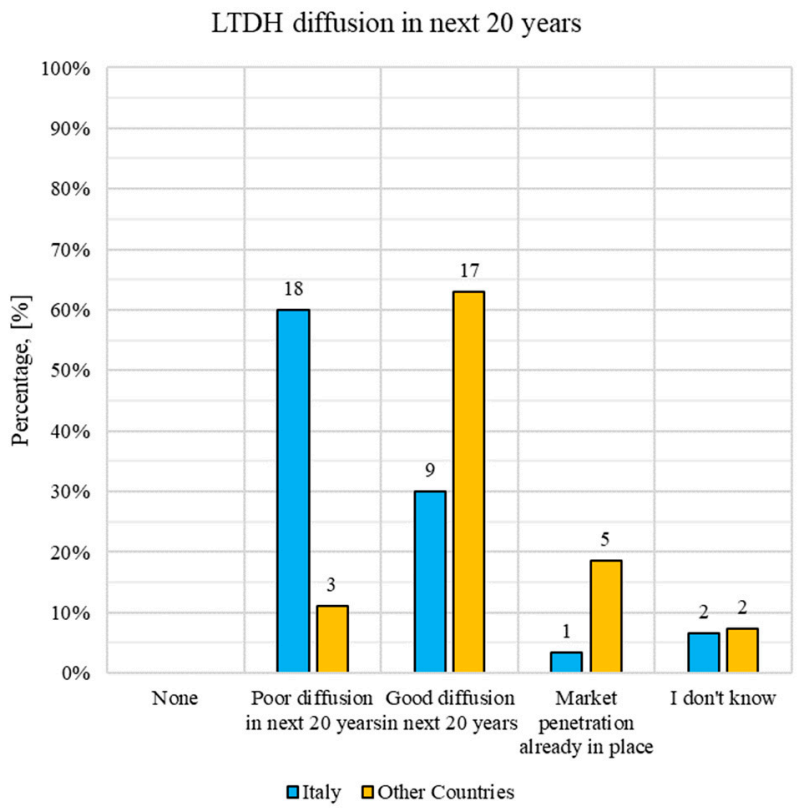

Figure 33. LTDH concept diffusion over the next 20 years.

LTDH diffusion in next 20 years

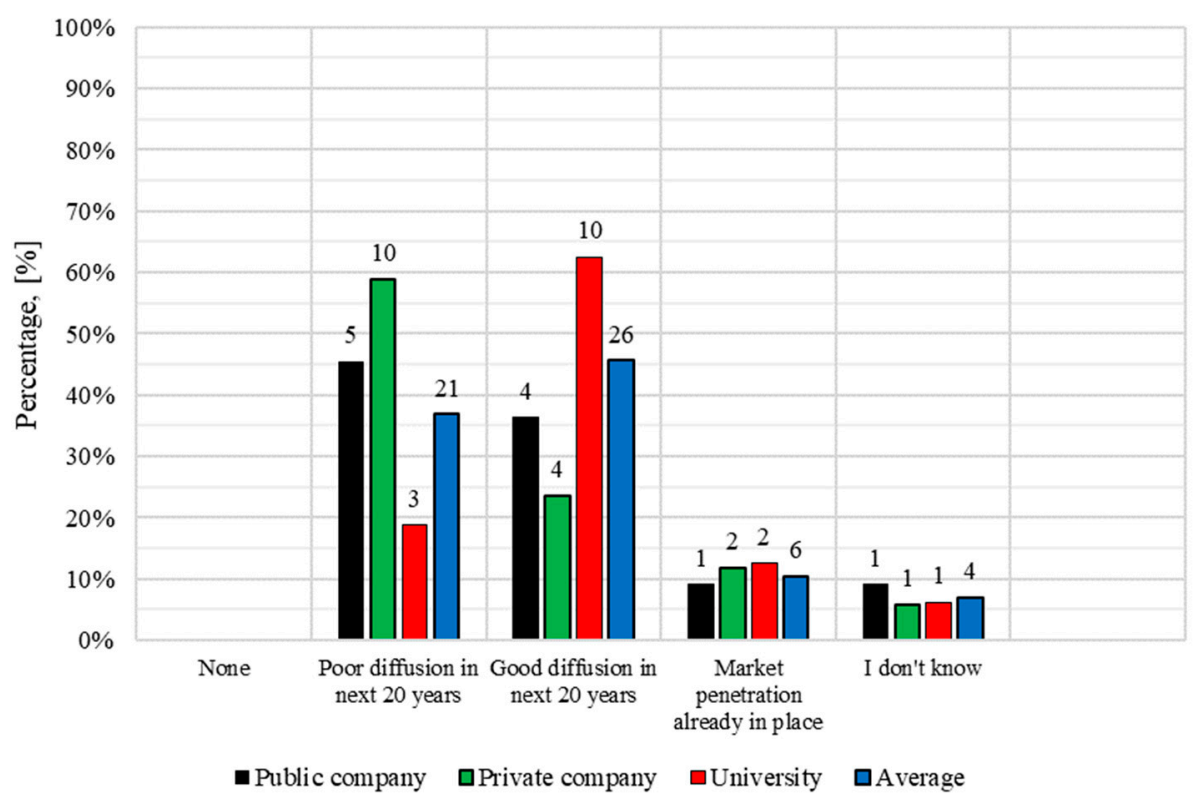

Figure 34. LTDH concept diffusion over the next 20 years as a function of the organization type. 
LTDH diffusion in next 20 years

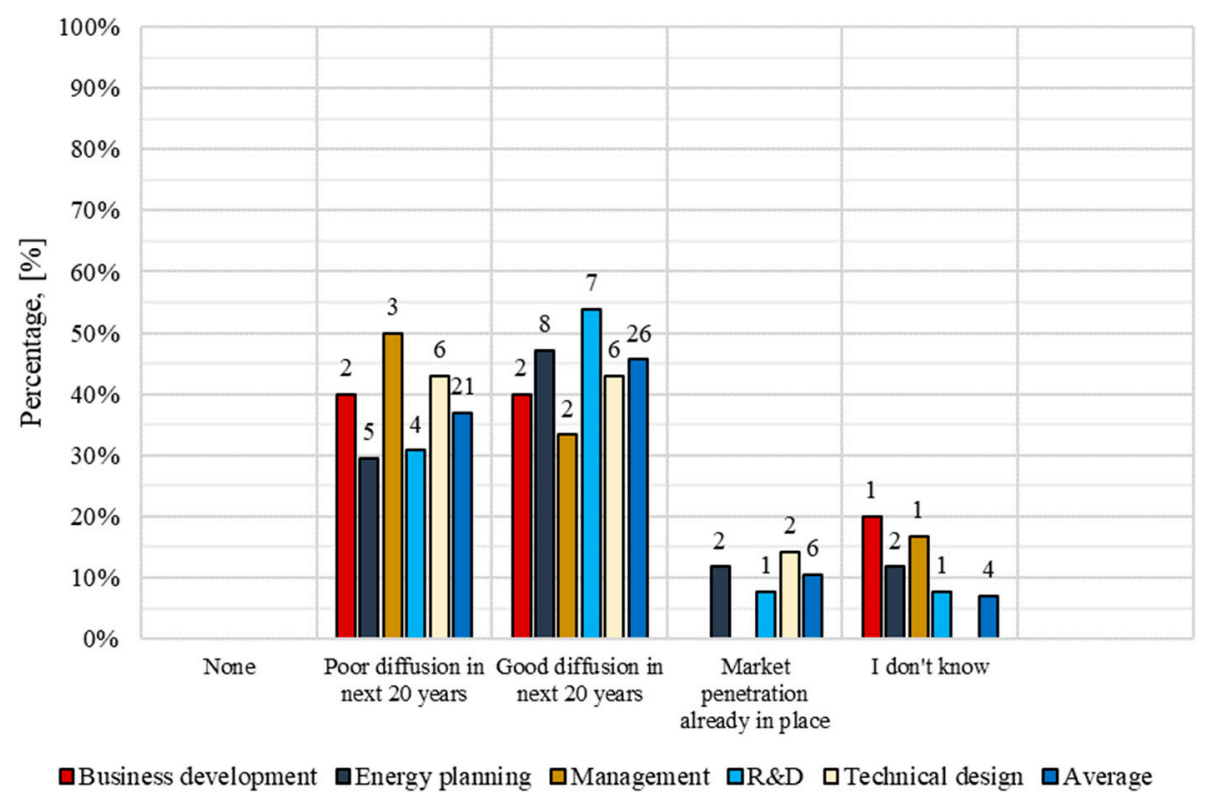

Figure 35. LTDH concept diffusion over the next 20 years as a function of the employment role.

LTDH diffusion in next 20 years

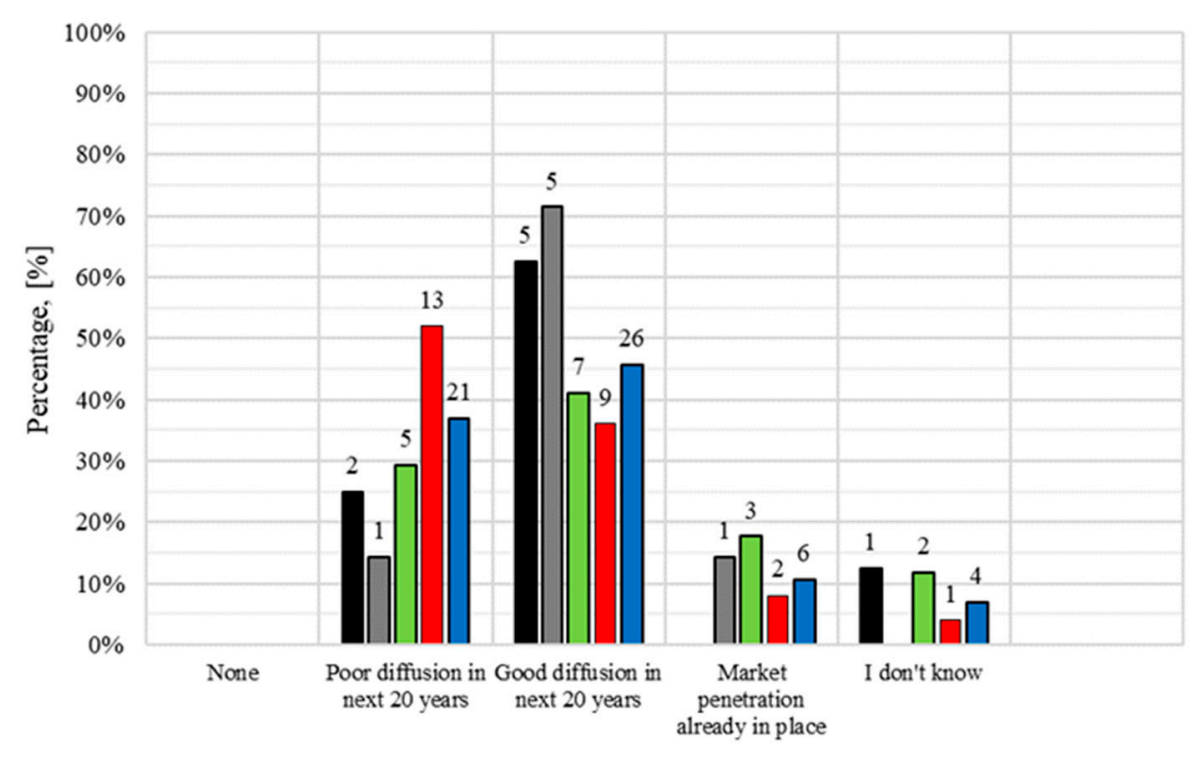

Less than 2 years $\square$ Between 2 and 5 years $\square$ Between 5 and 10 years $\square$ More than 10 years $\square$ Average

Figure 36. LTDH concept diffusion over the next 20 years as a function of working experience.

\subsection{Experts' Open Considerations about LTDH}

Some participants proposed interesting considerations about the LTDH concept at the end of the survey. A list of the most relevant follows:

\section{Economic considerations.}

a. Because of the technical and economic limitations in the retrofit of existing DH networks, the LTDH approach can be more easily applied in new DH networks. Given that it is reasonable to expect a higher number of new $\mathrm{DH}$ projects where a low $\mathrm{DH}$ penetration is currently present, LTDH vision seems to have the greatest potential in these areas. 
b. A reduction of the initial investment would be possible if both heating and cooling demands were supplied with a single energy distribution network.

c. Legislative, regulatory, and incentive strategies have to be promulgated by national governments to promote the implementation of LTDH systems. In fact, thermal loss reduction is not sufficient to justify the investment and secure a low pay back period.

2. Technical considerations - concerns about the need to design larger diameter pipelines to supply high thermal demands in LTDH systems with respect to traditional DH systems.

a. Regardless of opinion, as shown in [26], the LTDH network requires a higher flow rate in comparison with traditional district heating only in the case that heat and cooling demands are not balanced.

b. Furthermore, a reduction of the heating demands to be supplied by the networks is ensured by the heat pumps installed in DH substations. At the evaporator site, in fact, a reduction factor equal to $(\mathrm{COP}-1) /(\mathrm{COP})$, where $\mathrm{COP}$ is the coefficient of performance of the heat pump, has to be applied.

3. Service reliability and redundancy.

a. Based on the presence of prosumers, whose behavior cannot be completely controlled by DH operators, some backup or integration devices have to be considered in the design phase.

b. Heat storage volumes should be considered when heat production and consumption cannot be contemporary. For this purpose, sensible or latent heat storage technologies can be evaluated in accordance with the work of [68].

\section{Conclusions}

The need to change the DH market in the direction of LTDH in accordance with [22] still requires many efforts from all stakeholders. The diffusion and further development of LTDH systems require not only technological progress, but also the definition of a strategy able to overcome the existing non-technological barriers. Such a strategy should involve all the stakeholders (i.e., citizens, municipalities, local and regional authorities, policy makers, the DH industry, universities, and research centers) in a co-design of LTDH systems. Based on the received answers from the expert opinion survey and the elaborated information, it is possible to synthetize the following considerations:

1. Communication channels. Sector conferences, seminars, and workshops represent the most preferred communication channels by the interviewed participants. Only few participants recognized other communication channels, such as peer-reviewed papers and plant visits.

2. Advantages of traditional DH systems with respect to individual heating systems. Participants agreed to the fact that higher efficiency and technology reliability are the most important. Only a small percentage of participants attributed importance to business profitability or to technology replicability.

3. Disadvantages of traditional DH systems with respect to individual heating systems. From the reported answers, it is clear that the high distribution thermal losses were the most important disadvantage of traditional DH. The influence of external conditions on the DH business model is also considered by some as a critical point for technology implementation.

4. Advantages of the LTDH approach with respect to traditional DH systems. Almost all the participants agreed to the fact that LTDH ensures a reduction of distribution heat losses and less complexity in the integration of renewable sources at generation plants. Only a small percentage of Italian participants believed that the higher environmental and energy performances represent an important advantage. Consequently, the Italian authorities should propose promotion actions to compel sector stakeholders to improve energy and environmental performances. 
5. Disadvantages of the LTDH approach with respect to traditional DH systems. To accelerate the transition to LTDH systems, dedicated actions have to be taken. First of all, current DH business models need to be changed in order to be applied to LTDH systems, ensuring profitability. Secondly, dedicated technological solutions are required to ensure existing supply conditions, especially in the case of network retrofitting.

6. Ranking of the barriers against the implementation of LTDH. It seems that Italian rankings were on average lower than those received from other participants. That is, the most important barriers were the need to modify existing business models, the high investment cost, the limited opportunities for existing substation retrofitting, and the contractual restrictions about supply temperature. A different opinion about the suggested lack of competence for the implementation of LTDH systems was found between Italian and other participants.

7. Diffusion of the LTDH concept in the next 20 years. Despite the need to move in an LTDH direction to ensure energy and decarbonization goals, only participants from other countries believed that a good diffusion would be possible in the next 20 years; for Italian participants, a poor diffusion of the LTDH concept was expected. This opinion can be justified by the fact that Italian DH plants are of recent construction and in most cases not yet completely amortized. In addition to this, the low renovation rate of existing Italian buildings compels managers to believe that high temperature supply is still necessary to ensure contractual supply conditions [51].

The following topics still need to be investigated for the success of the LTDH concept:

- dedicated business models to the LTDH concept based on the prosumers concept and on the modification of the existing energy self-consumption model in Italian regulatory frameworks;

- innovative and high efficiency devices able to locally boost the supply temperature at the values required by contract and able to be installed in available spaces;

- identification of the best control strategies to manage LTDH systems in the case of contemporary heating and cooling demands.

Starting from the results achieved through the expert opinion survey, it will be possible to build a strategy for the development of LTDH systems. In particular, the realization of demonstrative plants in specific pilot cases, where an LTDH system is co-designed with the all stakeholders, is crucial for an effective promotion and diffusion of an LTDH approach, especially in Italy and Southern Europe.

Author Contributions: M.P. conducted the conceptualization and the methodology of the expert opinion survey; A.G. prepared the survey and was in charge of the data analysis and the preparation of the original draft; E.P. reviewed the original draft; C.S. provided comments and supported the study design. All authors have read and agreed to the published version of the manuscript.

Funding: This research was funded by EIT Climate-KIC Association of the European Institute of Innovation and Technology, which co-financed the "iEnergyDistrict" project. EIT Climate-KIC is a European knowledge and innovation community working towards a climate-resilient society founded on a circular and zero-carbon economy.

Acknowledgments: The authors acknowledge all the experts and the DH associations that answered the survey and in particular the AIRU (Associazione Italiana Riscaldamento Urbano), who shared the survey and thus made it possible to receive a sufficient number of answers to ensure statistical analysis.

Conflicts of Interest: The authors declare that there is no conflict of interest.

\section{Appendix A}

Survey questions and answers are reported below in Tables A1 and A2. 
Table A1. The expert opinion survey questions.

\begin{tabular}{|c|c|}
\hline & The Survey Questions \\
\hline \multirow{5}{*}{$\begin{array}{c}\text { Part 1: } \\
\text { Professional Status }\end{array}$} & 1.1 In what of the following organizations do you work? \\
\hline & 1.2 In which country is your organization located? \\
\hline & 1.3 What is your expertise area within the organization? \\
\hline & 1.4 What is your expertise area in district heating? \\
\hline & 1.5 How long do you work in the district heating sector? \\
\hline \multirow{3}{*}{$\begin{array}{c}\text { Part 2: } \\
\text { LTDH: The First Approach }\end{array}$} & 2.1 Have you ever heard about "low temperature district heating"? \\
\hline & $\begin{array}{l}2.2 \text { When do you hear about the concept of "low temperature district } \\
\text { heating" for the first time? }\end{array}$ \\
\hline & $\begin{array}{l}2.3 \text { Through which channel do you hear about the concept of "low } \\
\text { temperature district heating" for the first time? }\end{array}$ \\
\hline \multirow{7}{*}{$\begin{array}{l}\text { Part 3: } \\
\text { LTDH: Your Opinion }\end{array}$} & $\begin{array}{l}\text { 3.1 In your opinion, what are the main advantages of existing traditional } \\
\text { district heating systems? }\end{array}$ \\
\hline & $\begin{array}{l}3.2 \text { In your opinion, what are the main disadvantages of existing } \\
\text { traditional district heating systems? }\end{array}$ \\
\hline & $\begin{array}{l}\text { 3.3 In your opinion, what are the main advantages of the low } \\
\text { temperature district heating plants in comparison with traditional ones? }\end{array}$ \\
\hline & $\begin{array}{l}\text { 3.4 In your opinion, what are the main disadvantages of the low } \\
\text { temperature district heating plants in comparison with traditional ones? }\end{array}$ \\
\hline & $\begin{array}{l}\text { 3.5 Are you able to rank the following barriers to adapt traditional } \\
\text { district heating systems to "low temperature district heating systems? }\end{array}$ \\
\hline & $\begin{array}{l}\text { 3.6 What future do you expect for low-temperature district heating } \\
\text { systems in your country? }\end{array}$ \\
\hline & $\begin{array}{l}\text { 3.7 Please, can you leave a comment about low temperature district } \\
\text { heating systems? }\end{array}$ \\
\hline
\end{tabular}

Table A2. The expert opinion survey questions.

Suggested Answers to the Expert Opinion Survey

\begin{tabular}{ll}
\hline Question 1.1 & $\square$ Public company \\
& $\square$ Private company \\
& $\square$ Private research center \\
& $\square$ University \\
& $\square$ Public Authority \\
& $\square$ Self-employed \\
& $\square$ Other \\
\hline Question 1.2 & Any country in the world is permitted as an answer. \\
\hline Question 1.3 & $\square$ Administrative/Legal/Authorization \\
& $\square$ Business development \\
& $\square$ Energy planning \\
& $\square$ Management \\
& $\square$ Research and development \\
& $\square$ Technical/Design \\
& $\square$ Other \\
\hline Question 1.4 & Answers are equal to those for Question 1.3. \\
\hline Question 1.5 & $\square$ Less than 2 years \\
& $\square$ Between 2 years and 5 years \\
& $\square$ Between 5 years and 10 years \\
& $\square$ More than 10 years
\end{tabular}


Table A2. Cont.

\begin{tabular}{|c|c|}
\hline \multicolumn{2}{|r|}{ Suggested Answers to the Expert Opinion Survey } \\
\hline Question 2.1 & $\begin{array}{l}\square \text { Yes } \\
\square \mathrm{No}\left({ }^{*}\right)\end{array}$ \\
\hline Question 2.2 & $\begin{array}{l}\square \text { Before } 2000 \\
\square \text { Between 2000-2010 } \\
\square \text { Between 2010-2017 } \\
\square \text { This year }\end{array}$ \\
\hline Question $2.3(* *)$ & $\begin{array}{l}\square \text { Sector conference/seminar/workshop } \\
\square \text { Peer-reviewed papers } \\
\square \text { Technical magazines/newspapers } \\
\square \text { Internet sites } \\
\square \text { Plant visits } \\
\square \text { Other }\end{array}$ \\
\hline Question 3.1 (**) $^{*}$ & $\begin{array}{l}\square \text { State-of-the-art technology/Reliability } \\
\square \text { Remunerative business model } \\
\square \text { Able to supply heat to new and existing buildings } \\
\square \text { Higher efficiency with respect to traditional decentralized plants } \\
\square \text { High replicability } \\
\square \text { Other }\end{array}$ \\
\hline Question $3.2(* *)$ & $\begin{array}{l}\square \text { Complex integration of renewable energy sources in the generation plant } \\
\square \text { High distribution heat losses } \\
\square \text { Business model influenced by several external factors such as fuel cost, electricity } \\
\text { selling price and incentives/Feed-in tariffs } \\
\square \text { High limitations to decentralized energy production (at customer level) } \\
\square \text { Environmental sustainability } \\
\square \text { High heating selling price } \\
\square \text { Technical and/or economic limitations for the integration with district cooling } \\
\text { systems } \\
\square \text { Other }\end{array}$ \\
\hline Question $3.3(* *)$ & $\begin{array}{l}\square \text { Reduction of distribution heat losses } \\
\square \text { Lower complexity in the integration of renewable energy sources at the generation } \\
\text { plant } \\
\square \text { Lower complexity in the integration of renewable energy sources at the customer } \\
\text { level } \\
\square \text { Reduction of operative costs } \\
\square \text { Higher environmental sustainability } \\
\square \text { Higher energy efficiency } \\
\square \text { Higher integration in district cooling systems } \\
\square \text { Other }\end{array}$ \\
\hline Question $3.4(* *)$ & $\begin{array}{l}\square \text { Business model still to be developed } \\
\square \text { Higher investment costs } \\
\square \text { The need to locally boost supply temperature depending on customer's } \\
\text { characteristics (i.e., old/new buildings) } \\
\square \text { More complex management of central heat production and distribution } \\
\square \text { More complex management of the overall system due to distributed energy } \\
\text { production required also at the customer level } \\
\square \text { Need to meter thermal energy fluxes to and from the network } \\
\square \text { The need to locally boost supply temperature for domestic hot water production } \\
\square \text { Other }\end{array}$ \\
\hline
\end{tabular}


Table A2. Cont.

\begin{tabular}{ll}
\hline \multicolumn{1}{c}{ Suggested Answers to the Expert Opinion Survey } \\
\hline Question 3.5 (**) & $\square$ High investment costs \\
& $\square$ The need to locally boost supply temperature \\
& $\square$ The need to modify existing business models \\
& $\square$ The metering of the thermal energy fluxes to and from the network \\
& $\square$ Contractual restrictions about supply temperature conditions \\
& $\square$ Limited opportunities for existing substation retrofitting \\
& $\square$ The relationship with the customer \\
& $\square$ Legislative/Regulatory/Authorization constraints \\
& $\square$ Conflictual relationship between the grid operator, the district heating plant \\
& manager and the eventual manager of the substation \\
& $\square$ Lack of the required technical competences \\
& $\square$ Other \\
\hline Question 3.6 & $\square$ None \\
& $\square$ Poor diffusion in the next 20 years \\
& $\square$ Good diffusion in the next 20 years \\
& $\square$ Market penetration already in place with good diffusion \\
& $\square$ I don't know \\
\hline Question 3.7 & Open form answer \\
\hline
\end{tabular}

$\left.{ }^{*}\right)$ In the case the participant answers "no," all the questions about LTDH are not required to be answered. $\left({ }^{* *}\right)$ More than one answer is possible for the question. $\left.{ }^{* * *}\right)$ Participants were asked to rank the identified barriers for the implementation of LTDH with a number from 1 (very low importance) to 5 (very high importance).

\section{References}

1. Ekins, P. Step changes for decarbonising the energy system: Research needs for renewables, energy efficiency and nuclear power. Energy Policy 2004, 32, 1891-1904. [CrossRef]

2. BP Energy Economics. 2018 BP Energy Outlook; BP p.l.c.: London, UK, 2018.

3. Connolly, D.; Lund, H.; Mathiesen, B.V.; Werner, S.; Möller, B.; Persson, U.; Boermans, T.; Trier, D.; Østergaard, P.A.; Nielsen, S. Heat Roadmap Europe: Combining district heating with heat savings to decarbonise the EU energy system. Energy Policy 2013, 65, 475-489. [CrossRef]

4. Cassitto, L. District heating systems in Europe. A review. Resour. Conserv. Recycl. 1990, 4, 271-281. [CrossRef]

5. Sayegh, M.A.; Danielewicz, J.; Nannou, T.; Miniewicz, M.; Jadwiszczak, P.; Piekarska, K.; Jouhara, H. Trends of European research and development in district heating technologies. Renew. Sustain. Energy Rev. 2017, 68, 1183-1192. [CrossRef]

6. Lake, A.; Rezaie, B.; Beyerlein, S. Review of district heating and cooling systems for a sustainable future. Renew. Sustain. Energy Rev. 2017, 67, 417-425. [CrossRef]

7. Rezaie, B.; Rosen, M.A. District heating and cooling: Review of technology and potential enhancements. Appl. Energy 2012, 93, 2-10. [CrossRef]

8. Li, H.; Svendsen, S. Energy and exergy analysis of low temperature district heating network. Energy 2012, 45, 237-246. [CrossRef]

9. Bianchini, A.; Guzzini, A.; Pellegrini, M.; Saccani, C. Natural gas distribution system: A statistical analysis of accidents data. Int. J. Press. Vessel. Pip. 2018, 168, 24-38. [CrossRef]

10. Werner, S. International review of district heating and cooling. Energy 2017, 137, 617-631. [CrossRef]

11. Lund, R.; Persson, U. Mapping of potential heat sources for heat pumps for district heating in Denmark. Energy 2016, 110, 129-138. [CrossRef]

12. Lauka, D.; Gusca, J.; Blumberga, D. Heat Pumps Integration Trends in District Heating Networks of the Baltic States. Procedia Comput. Sci. 2015, 52, 835-842. [CrossRef]

13. Averfalk, H.; Ingvarsson, P.; Persson, U.; Gong, M.; Werner, S. Large heat pumps in Swedish district heating systems. Renew. Sustain. Energy Rev. 2017, 79, 1275-1284. [CrossRef]

14. Ericsson, K.; Werner, S. The introduction and expansion of biomass use in Swedish district heating systems. Biomass Bioenergy 2016, 94, 57-65. [CrossRef] 
15. Soltero, V.M.; Chacartegui, R.; Ortiz, C.; Velázquez, R. Potential of biomass district heating systems in rural areas. Energy 2018, 156, 132-143. [CrossRef]

16. Vallios, I.; Tsoutsos, T.; Papadakis, G. Design of biomass district heating systems. Biomass Bioenergy 2009, 33, 659-678. [CrossRef]

17. Reiter, P.; Poier, H.; Holter, C. BIG Solar Graz: Solar District Heating in Graz-500,000 $\mathrm{m}^{2}$ for $20 \%$ Solar Fraction. Energy Procedia 2016, 91, 578-584. [CrossRef]

18. Best, I.; Orozaliev, J.; Vajen, K. Economic comparison of low-temperature and ultra-low-temperature district heating for new building developments with low heat demand densities in Germany. Int. J. Sustain. Energy Plan. Manag. 2018, 16, 45-60.

19. Gudmundsson, O.; Thorsen, J.E.; Zhang, L. Cost analysis of district heating compared to. Trans. Ecol. Environ. 2013, 176, 1743-3541.

20. Reidhav, C.; Werner, S. Profitability of sparse district heating. Appl. Energy 2008, 85, 867-877. [CrossRef]

21. Comodi, G.; Lorenzetti, M.; Salvi, D.; Arteconi, A. Criticalities of district heating in Southern Europe: Lesson learned from a CHP-DH in Central Italy. Appl. Therm. Eng. 2017, 112, 649-659. [CrossRef]

22. Lund, H.; Werner, S.; Wiltshire, R.; Svendsen, S.; Thorsen, J.E.; Hvelplund, F.; Mathiesen, B.V. 4th Generation District Heating (4GDH): Integrating smart thermal grids into future sustainable energy systems. Energy 2014, 68, 1-11. [CrossRef]

23. Averfalk, H.; Werner, S.; Felsmann, C.; Ruhling, K.; Wiltshire, R.; Svendsen, S. Annex XI Final Report. Transformation Roadmap from High to Low Temperature District Heating Systems; IEA: Paris, France, 2017.

24. Lund, R.; Østergaard, D.S.; Yang, X.; Mathiesen, B.V. Comparison of Low-temperature District Heating Concepts in a Long-Term Energy System Perspective. Int. J. Sustain. Energy Plan. Manag. 2017, 12, 5-18.

25. Colmenar-Santos, A.; Rosales-Asensio, E.; Borge-Diez, D.; Blanes-Peiró, J.-J. District heating and cogeneration in the EU-28: Current situation, potential and proposed energy strategy for its generalisation. Renew. Sustain. Energy Rev. 2016, 62, 621-639. [CrossRef]

26. Pellegrini, M.; Bianchini, A. The innovative concept of cold district heating networks: A literature review. Energies 2018, 11, 236. [CrossRef]

27. Schmidt, D.; Kallert, A.; Blesl, M.; Li, H.; Svendsen, S.; Nord, N.; Sipilä, K.; Rämä, M.; Gudmundson, O.; Kuosa, M.; et al. DHC Annex TS1—Low Temperature District Heating for Future Energy Systems; AGFW-Project Company: Frankfurt am Main, Germany, 2017; ISBN 3899990706.

28. De Uribarri, P.M.Á.; Eicker, U.; Robinson, D. Energy performance of decentralized solar thermal feed-in to district heating networks. Energy Procedia 2017, 116, 285-296. [CrossRef]

29. Parida, B.; Iniyan, S.; Goic, R. A review of solar photovoltaic technologies. Renew. Sustain. Energy Rev. 2011, 15, 1625-1636. [CrossRef]

30. Bianchini, A.; Gambuti, M.; Pellegrini, M.; Saccani, C. Performance analysis and economic assessment of different photovoltaic technologies based on experimental measurements. Renew. Energy 2016, 85, 1-11. [CrossRef]

31. Ni, L.; Dong, J.; Yao, Y.; Shen, C.; Qv, D.; Zhang, X. A review of heat pump systems for heating and cooling of buildings in China in the last decade. Renew. Energy 2015, 84, 30-45. [CrossRef]

32. Tian, Y.; Zhao, C.Y. A review of solar collectors and thermal energy storage in solar thermal applications. Appl. Energy 2013, 104, 538-553. [CrossRef]

33. Bianchini, A.; Guzzini, A.; Pellegrini, M.; Saccani, C. Performance assessment of a solar parabolic dish for domestic use based on experimental measurements. Renew. Energy 2019, 133, 382-392. [CrossRef]

34. Chow, T.T. A review on photovoltaic/thermal hybrid solar technology. Appl. Energy 2009, 87, 365-379. [CrossRef]

35. Bianchini, A.; Guzzini, A.; Pellegrini, M.; Saccani, C. Photovoltaic/thermal (PV/T) solar system: Experimental measurements, performance analysis and economic assessment. Renew. Energy 2017, 111, 543-555. [CrossRef]

36. Dalla Rosa, A.; Li, H.; Svendsen, S.; Werner, S.; Persson, U.; Ruehling, K.; Felsmann, C.; Crane, M.; Burzynski, R.; Bevilacqua, C. Annex X Final Report. Toward 4th Generation District Heating: Experience and Potential of Low-Temperatur District Heating; IEA: Paris, France, 2014.

37. Lund, H.; Østergaard, P.A.; Connolly, D.; Mathiesen, B.V. Smart energy and smart energy systems. Energy 2017, 137, 556-565. [CrossRef] 
38. Østergaard, D.S.; Svendsen, S. Replacing critical radiators to increase the potential to use low-temperature district heating-A case study of 4 Danish single-family houses from the 1930s. Energy 2016, 110, 75-84. [CrossRef]

39. Østergaard, D.; Svendsen, S. Space heating with ultra-low-temperature district heating-A case study of four single-family houses from the 1980s. Energy Procedia 2017, 116, 226-235. [CrossRef]

40. Brand, L.; Calvén, A.; Englund, J.; Landersjö, H.; Lauenburg, P. Smart district heating networks-A simulation study of prosumers' impact on technical parameters in distribution networks. Appl. Energy 2014, 129, $39-48$. [CrossRef]

41. Brange, L.; Englund, J.; Lauenburg, P. Prosumers in district heating networks-A Swedish case study. Appl. Energy 2016, 164, 492-500. [CrossRef]

42. Mathiesen, B.V.; Lund, H.; Connolly, D.; Wenzel, H.; Ostergaard, P.A.; Möller, B.; Nielsen, S.; Ridjan, I.; KarnOe, P.; Sperling, K.; et al. Smart Energy Systems for coherent 100\% renewable energy and transport solutions. Appl. Energy 2015, 145, 139-154. [CrossRef]

43. Lund, H.; Connolly, D.; Ostergaard, P.A.; Ridjan, I.; Vad Mathiesen, B.; Hvelplund, F.; Thellufsen, J.Z.; Sorknaes, P. Energy storage and Smart Energy Systems. Int. J. Sustain. Energy Plan. Manag. 2016, 11.

44. Nord, N.; Løve Nielsen, E.K.; Kauko, H.; Tereshchenko, T. Challenges and potentials for low-temperature district heating implementation in Norway. Energy 2018, 151, 889-902. [CrossRef]

45. Li, H.; Wang, S.J. Challenges in Smart Low-temperature District Heating Development. Energy Procedia 2014, 61, 1472-1475. [CrossRef]

46. Gadd, H.; Werner, S. Fault detection in district heating substations. Appl. Energy 2015, 157, 51-59. [CrossRef]

47. Xue, P.; Zhou, Z.; Fang, X.; Chen, X.; Liu, L.; Liu, Y.; Liu, J. Fault detection and operation optimization in district heating substations based on data mining techniques. Appl. Energy 2017, 205, 926-940. [CrossRef]

48. Averfalk, H.; Werner, S. Novel low temperature heat distribution technology. Energy 2018, 145, 526-539. [CrossRef]

49. Yang, X.; Li, H.; Svendsen, S. Evaluations of different domestic hot water preparing methods with ultra-low-temperature district heating. Energy 2016, 109, 248-259. [CrossRef]

50. Yang, X.; Li, H.; Svendsen, S. Decentralized substations for low-temperature district heating with no Legionella risk, and low return temperatures. Energy 2016, 110, 65-74. [CrossRef]

51. Pellegrini, M.; Bianchini, A.; Guzzini, A.; Saccani, C. Classification through analytic hierarchy process of the barriers in the revamping of traditional district heating networks into low temperature district heating: An Italian case study. Int. J. Sustain. Energy Plan. Manag. 2019, 20, 51-66.

52. Astiaso Garcia, D.; Barbanera, F.; Cumo, F.; Di Matteo, U.; Nastasi, B.; Astiaso Garcia, D.; Barbanera, F.; Cumo, F.; Di Matteo, U.; Nastasi, B. Expert Opinion Analysis on Renewable Hydrogen Storage Systems Potential in Europe. Energies 2016, 9, 963. [CrossRef]

53. Catenacci, M.; Verdolini, E.; Bosetti, V.; Fiorese, G. Going electric: Expert survey on the future of battery technologies for electric vehicles. Energy Policy 2013, 61, 403-413. [CrossRef]

54. Bosetti, V.; Catenacci, M.; Fiorese, G.; Verdolini, E. The future prospect of PV and CSP solar technologies: An expert elicitation survey. Energy Policy 2012, 49, 308-317. [CrossRef]

55. Fiorese, G.; Catenacci, M.; Verdolini, E.; Bosetti, V. Advanced biofuels: Future perspectives from an expert elicitation survey. Energy Policy 2013, 56, 293-311. [CrossRef]

56. Maestas, C. Expert Surveys as a Measurement Tool: Challenges and New Frontiers; Atkeson, L.R., Alvarez, R.M., Eds.; Oxford University Press: Oxford, UK, 2016; Volume 1.

57. Eraut, M. Expert and Expertise: Meanings and Perspectives. Learn. Health Soc. Care 2005, 4, 173-179. [CrossRef]

58. Çomaklı, K.; Yüksel, B.; Çomaklı, Ö. Evaluation of energy and exergy losses in district heating network. Appl. Therm. Eng. 2004, 24, 1009-1017. [CrossRef]

59. Nuytten, T.; Claessens, B.; Paredis, K.; Van Bael, J.; Six, D. Flexibility of a combined heat and power system with thermal energy storage for district heating. Appl. Energy 2013, 104, 583-591. [CrossRef]

60. Rämä, M.; Wahlroos, M. Introduction of new decentralised renewable heat supply in an existing district heating system. Energy 2018, 154, 68-79. [CrossRef]

61. Pirouti, M.; Bagdanavicius, A.; Ekanayake, J.; Wu, J.; Jenkins, N. Energy consumption and economic analyses of a district heating network. Energy 2013, 57, 149-159. [CrossRef] 
62. Olsthoorn, D.; Haghighat, F.; Mirzaei, P.A. Integration of storage and renewable energy into district heating systems: A review of modelling and optimization. Sol. Energy 2016, 136, 49-64. [CrossRef]

63. Persson, U.; Werner, S. Heat distribution and the future competitiveness of district heating. Appl. Energy 2011, 88, 568-576. [CrossRef]

64. Rosada, J. Characteristics of District Heating-Advantages and Disadvantages. Energy Build. 1988, 12, $163-171$. [CrossRef]

65. Schuman, H.; Presser, S. The Open and Closed Question. Am. Sociol. Rev. 1979, 44, 692. [CrossRef]

66. Züll, C. Open-Ended Questions. GESIS Survey Guidelines; GESIS-Leibniz Institute for the Social Sciences: Mannheim, Germany, 2016.

67. Lund, H.; Østergaard, P.A.; Chang, M.; Werner, S.; Svendsen, S.; Sorknæs, P.; Thorsen, J.E.; Hvelplund, F.; Mortensen, B.O.G.; Mathiesen, B.V.; et al. The status of 4th generation district heating: Research and results. Energy 2018, 164, 147-159. [CrossRef]

68. Flores, J.; Espagnet, A.; Chiu, J.; Martin, V.; Lacarriere, B. Techno-Economic Assessment of Active Latent Heat Thermal EnergyStorage Systems with Low-Temperature District Heating. Int. J. Sustain. Energy Plan. Manag. 2017, 13, 5-18.

(C) 2020 by the authors. Licensee MDPI, Basel, Switzerland. This article is an open access article distributed under the terms and conditions of the Creative Commons Attribution (CC BY) license (http://creativecommons.org/licenses/by/4.0/). 